\title{
Thalamic interactions of cerebellum and basal ganglia
}

\author{
Andreas Hintzen ${ }^{1}$ Esther Annegret Pelzer ${ }^{1} \cdot$ Marc Tittgemeyer $^{1}(1)$ \\ Received: 4 May 2017 / Accepted: 29 November 2017 / Published online: 9 December 2017 \\ (c) The Author(s) 2017. This article is an open access publication
}

\begin{abstract}
Cerebellum and basal ganglia are reciprocally interconnected with the neocortex via oligosynaptic loops. The signal pathways of these loops predominantly converge in motor areas of the frontal cortex and are mainly segregated on subcortical level. Recent evidence, however, indicates subcortical interaction of these systems. We have reviewed literature that addresses the question whether, and to what extent, projections of main output nuclei of basal ganglia (reticular part of the substantia nigra, internal segment of the globus pallidus) and cerebellum (deep cerebellar nuclei) interact with each other in the thalamus. To this end, we compiled data from electrophysiological and anatomical studies in rats, cats, dogs, and non-human primates. Evidence suggests the existence of convergence of thalamic projections originating in basal ganglia and cerebellum, albeit sparse and restricted to certain regions. Four regions come into question to contain converging inputs: (1) lateral parts of medial dorsal nucleus (MD); (2) parts of anterior intralaminar nuclei and centromedian and parafascicular nuclei (CM/Pf); (3) ventromedial nucleus (VM); and (4) border regions of cerebellar and ganglia terminal territories in ventral anterior and ventral lateral nuclei (VA-VL). The amount of convergences was found to exhibit marked interspecies differences. To explain the rather sparse convergences of projection territories and to estimate their physiological relevance, we present two conceivable principles of anatomical organization: (1) a "core-and-shell" organization, in which a central core is exclusive to one projection system, while peripheral shell regions intermingle and occasionally converge with other projection systems and (2) convergences that are characteristic to distinct functional networks. The physiological relevance of these convergences is not yet clear. An oculomotor network proposed in this work is an interesting candidate to examine potential ganglia and cerebellar subcortical interactions.
\end{abstract}

Keywords Basal ganglia $\cdot$ Cerebellum $\cdot$ Thalamus $\cdot$ Satellite systems $\cdot$ Connectivity

\section{Introduction}

\section{Anatomical background}

Cerebellum and basal ganglia are oligosynaptically interconnected with the cerebral cortex (Nieuwenhuys et al. 2008; Haber et al. 2012; Voogd and Ruigrok 2012). Both structures

In memoriam of Andreas Hintzen: sadly, Andreas' recently deceased before he could finish this work-we would have greatly appreciated to accomplish this article together with him, and feel this as a tremendous loss.

Esther Annegret Pelzer

esther.pelzer@sf.mpg.de

$\triangle$ Marc Tittgemeyer

marc.tittgemeyer@sf.mpg.de

1 Max-Planck-Institute for Metabolism Research Cologne, Gleueler Str. 50, 50931 Cologne, Germany receive the bulk of their afferences from the cerebral cortex and send major projections back to the cortex via the thalamus. The cerebellum receives its cortical input from motor and sensory areas. These projections are mainly relayed in the pontine nuclei and traverse the medial cerebellar peduncle to innervate the cerebellar cortex. Here, microcircuitry processes this input and sends the resulting output via its Purkinje cells almost entirely to the deep cerebellar nuclei (DCN). These constitute the main output structures of the cerebellum and project to a great extent via the superior cerebellar peduncle to the thalamus. The main neurotransmitter of these projections is glutamate, which elicits mostly excitatory cell responses. Other neurotransmitters, as well as inhibitory and complex response patterns, have also been described (Uusisaari and Knöpfel 2012; Buford et al. 1996). In the thalamus, these signals are relayed for the most part to the primary motor area of the cortex; further projections to premotor and prefrontal areas exhibit a decreasing 
density gradient (Sakai et al. 2002). The information flow between cerebral cortex and basal ganglia is organized similarly: afferences originating from motor, prefrontal, and orbitofrontal cortical areas innervate the striatum; interactions between their projection territories at the level of the striatum are extensive. These interactions occur in specific regions in which convergence of terminal fields from different functional cortical regions is found. Incoming signals are processed within internal basal ganglia circuitries and outcome is conveyed to the main output structures: the internal part of the globus pallidus (GPi) and the reticular part of the substantia nigra $(\mathrm{SNr})$. The bulk of this output reaches the thalamus and exerts a GABAergic inhibitory influence on projection neurons that target the cerebral cortex. This anatomy suggests a circular information flow (Haber 2016).

These cerebello-thalamo-cortical and basal gangliothalamo-cortical loops are topographically organized, constituting anatomically and functionally segregated channels which are relayed in different thalamic nuclei [see Fig. 7 in Middleton and Strick (2000)]. An interaction of cerebellar and basal ganglia loops occurs mainly in motor regions of the cerebral cortex (Kuramoto et al. 2009). Subcortical interactions, however, are often neglected when modeling brain function on a systemic level (Doya 2000). Transneuronal tracing studies in primates point towards substantial subcortical interactions of these two systems. Those studies revealed trisynaptic projections of the cerebellum via thalamus and striatum into the external part of the globus pallidus (Hoshi et al. 2005). Similar projections of the basal ganglia to the cerebellum have been shown to originate in the subthalamic nucleus, being relayed to the cerebellar cortex via pontine nuclei and/or tegmental pontine reticular nucleus (Bostan et al. 2010). Further evidence of subcortical interaction exists in the brainstem [e.g., superior colliculus in Westby et al. (1994)] and in the thalamus (Chevalier and Deniau 1982; Nambu et al. 1988; Sakai and Patton 1993; Sakai et al. 1996). However, discrepancies exist concerning the amount of these convergences. It is rather difficult to compare the quantification of investigated neurons in electrophysiological studies, light microscopy, retrograde tracing studies, and anterograde studies. Descriptions of projection density were commonly performed using categories such as "sparse", "moderate", "substantial", or "dense". Although synapses cannot be resolved by light microscopy, the general morphology of axon terminals allows for an estimation of the density of the projection. This information is, e.g., inaccessible by retrograde tracing studies. Since the morphology of axon terminals can differ substantially in its collateralization and number of developed synapses, the meaningfulness of such quantifications is limited. To enable a better comparability between such studies, we indicate the relative frequency of neurons in which converging inputs could be shown in relation with the total number of investigated neurons. In this work, we investigated to what degree convergences occur in the thalamus. To provide potential explanatory approaches for conflicting reports, we sorted the studies by species, employed methods as well as thalamic regions.

\section{Inclusion criteria, definitions, and procedures}

\section{Animal models}

Studies in species of three taxonomic orders were included in this work: (1) rodents, consisting of studies in rats; (2) carnivores, mainly consisting of studies in cats and occasional studies in dogs; and (3) primates, mainly consisting of investigations in representatives of the genus macaca and sporadic studies in other genera (e.g., squirrel monkeys). This allows for a coarse interspecies comparison of interactions in the thalamus. In rodents, we have limited ourselves to the example of studies in rats, as these are to date more extensively discussed; for work on anatomical organization in mice, please refer, e.g., to the Allen Mouse Connectivity Atlas (http://connectivity.brain-map.org) or, specifically, for basal ganglia and cerebellar interaction in mice, e.g., Chen et al. (2014), Neychev et al. (2008).

\section{Projection pattern definition}

We name regions that are innervated by a given structure the (terminal) territory of that structure (Percheron et al. 1996). Two territories within a thalamic nucleus are defined as being segregated if they are not innervated by the same region (Fig. 1a) and have no informational exchange with adjacent regions. Due to resolution by the applied methods, a differentiation from partial overlap especially in boundary regions is, however, discussable. To that end, it also needs to be noted that any empirical approaches for discovering connections have apertures that are tuned to particular scales and data features: a given method has only access to a limited range of features and can only partially capture connections at a certain level of detail, i.e., at a restricted level of organization. Hence, a distinct segregation, while theoretical possible, will be empirically hard to be evidenced. Converging projections are such in which a thalamic neuron receives input from both projection systems, i.e., projections end in the same terminal field; this overlap makes an informational exchange between two (or more) projections possible. Electrophysiological and electronmicroscopical studies provide solid means in the case of convergences being present, but due to relatively small sample sizes, the lack of convergences being observed does not prove that they indeed do not exist. Anatomical tracing studies employing light microscopy 
(A)

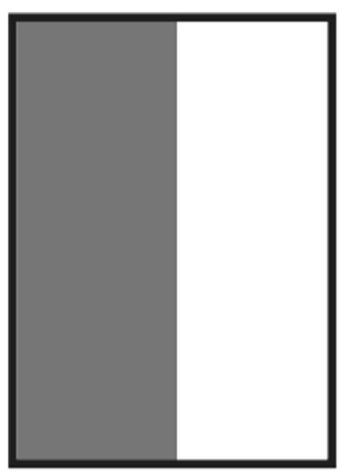

(B)

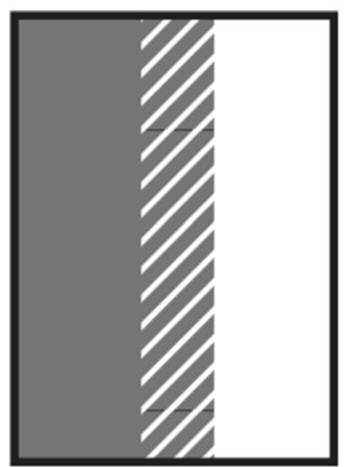

(C)

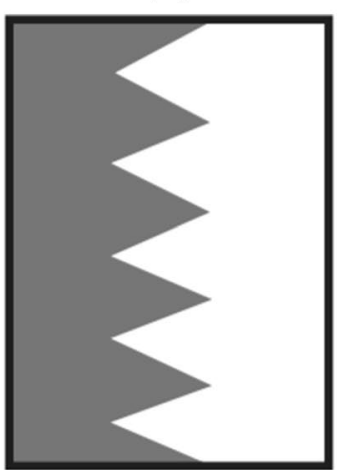

Fig. 1 Projection patterns. Three principle projection patterns have been described in studies that examined the relation of cerebellar and ganglia territories: a two territories within a thalamic nucleus are defined as being segregated if they do not innervate the same region and have no informational exchange with adjacent regions. b Converging projections are discussed if projections appear in the same terminal field. c Interdigitating territories lie close together and reach into each other, mostly without overlapping on the other hand provide a relatively complete picture of the projection territories, but cannot prove convergence in regions of overlapping territories due to the limited resolution. Therefore, we consider overlapping territories as being sites of potential convergence (Fig. 1b). Another putative pattern of interrelations between terminal territories is often termed "interdigitating" in the reviewed literature (Fig. 1c). Here, territories lie in close proximity and reach into each other, mostly without overlapping [cf. Fig. 5, left side in Sakai et al. (1996)], connections can form patches of varied regularity (Goldman-Rakic 1984), or their terminal fields can display striking interrelation. This projection pattern thus indicates rather segregated territories. On the other hand, convergences in border areas have been observed, and oligosynaptic communication via local interneurons, as well as modulatory effects via volume transmission, are also conceivable.

\section{Thalamus nomenclature and nuclei border definitions}

The thalamus can be divided into a multitude of different nuclei with varieties based on interspecies differences (Hassler 1950; Olszewski 1952; Snider and Niemer 1961; Pellegrino and Cushman 1967; Berman 1968; Schaltenbrand et al. 1977; Berman and Jones 1982; Paxinos and Watson 2006; Jones 2007), different approaches to define borders (Krauth et al. 2010)], and different schools of nomenclature (Dewulf and van Winsen 1971). Consequently, the attribution of interspecies equivalent regions is highly ambiguous. A list of nuclei and their interspecies equivalents, as well as synonyms between different nomenclatures can be found in Jones (2007). To enable a comparison of results in different species, we explored the nomenclature and border definitions of individual nuclei and their interspecies equivalents wherever possible. In general, two regions regarding inputs from cerebellum and basal ganglia can be recognized: (1) parts of the thalamus that lie medial to and include the internal medullary lamina; (2) parts of the thalamus that are situated laterally and anteriorly hereto. Figure 2 shows a schematically overview of the involved region, adapted from Nieuwenhuys et al. (2008). The latter is generally termed "motor thalamus" and consists of the ventral anterior and ventral lateral nuclei (VA-VL). VA-VL concavely clings to the medial thalamic region. The medial border is defined by the internal medullary lamina as well as anterior and lateral thalamic nuclei. Posteriorly, it transitions into the ventral posterior nucleus (VP). Based on Jones (2007), the following subnuclei are distinguished in primates. A ventral anterior nucleus (VA) contains a magnocellular (VAmc) component. VAmc misses in cats and dogs, and a paralaminar region (VApl) might represent its equivalent (Sakai and Patton 1993). Furthermore, a ventral lateral nucleus (VL) with an anterior (VLa; pallidal territory) and a posterior (VLp; cerebellar territory) component is distinguished. Olszewski (1952) divided the primate VLp into four further subdivisions: area $\mathrm{X}$ (X; anteromedial); pars postrema of ventral lateral nucleus (VLps; posterodorsal); the oral part of the ventral posterior lateral nucleus (VPLo; ventral); and a ventromedial nucleus (VM), which is sometimes also referred to as medial part of the ventral lateral nucleus (VLm). It is difficult to differentiate VM from other nuclei based on cytoarchitectonic features. Hence, the interspecies equivalent of this nucleus is controversial, some assigning it to $\mathrm{VA}$, others to $\mathrm{VL}$ or $\mathrm{VP}$ (Jones 2007). In cats and dogs, a main division (VL) and a dorsal part (VLd) are distinguished (Sakai and Patton 1993). According to Jones (2007), VPLo represents the equivalent of the ventral intermediate nucleus (Vim) in 
Fig. 2 Thalamic nuclei with cerebellar or pallidal afferents. In this horizontal view, nuclei receiving input from either the cerebellum, substantia nigra, or pallidum are highlighted in green. Modified after Nieuwenhuys (2008). Abbreviations of thalamic nuclei are based on Jones nomenclature (2007)

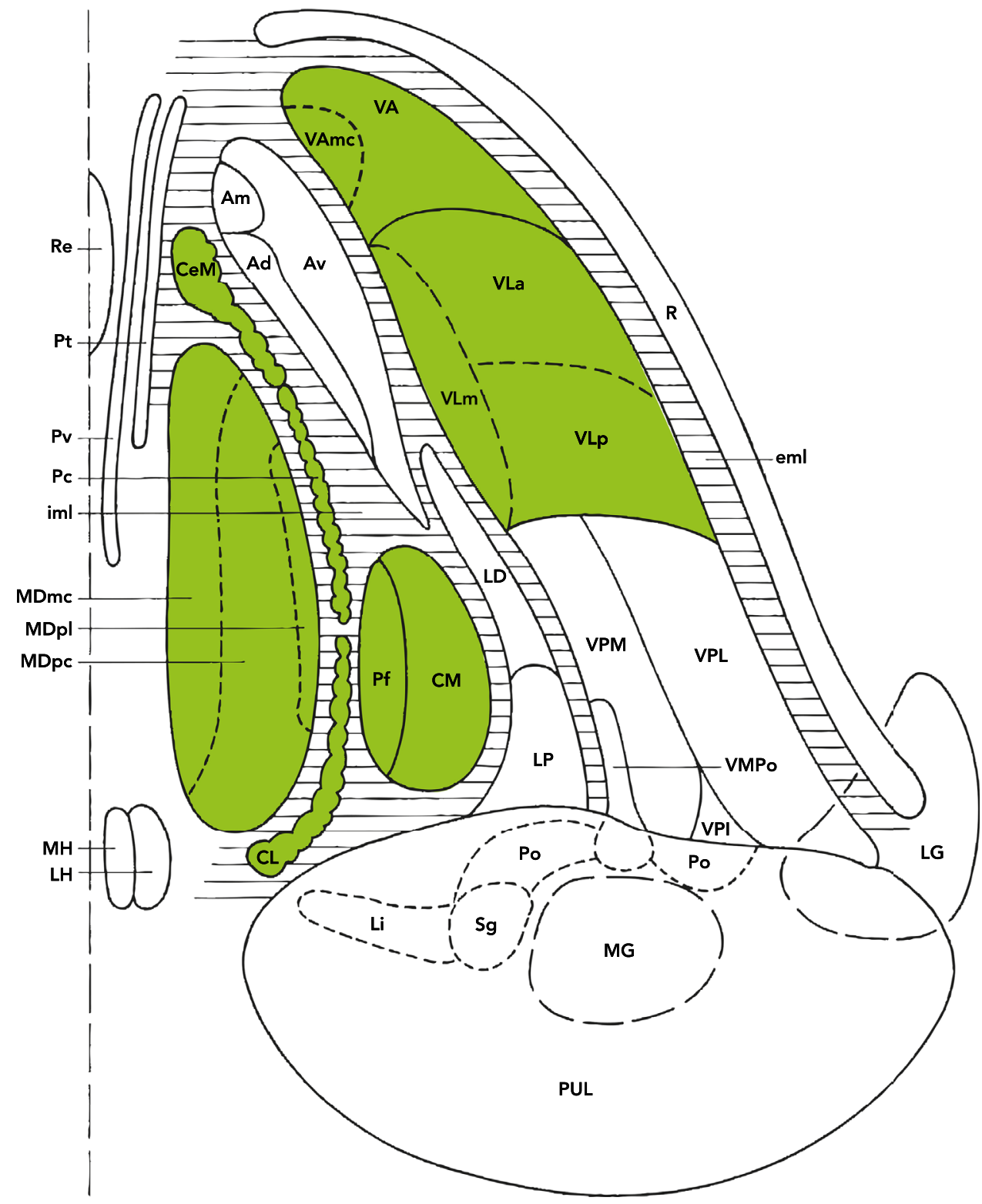

humans (Hassler 1950), an important target in deep brain stimulation to alleviate symptoms in Parkinson's disease. The relevant nuclei in the medial region comprise of the medial dorsal (MD) and intralaminar (IL) nuclei. The MD is situated centrally in the thalamus, almost completely surrounded by the internal medullary lamina. Only medially, it does border the third ventricle. The MD consists of three subdivisions: a medially situated magnocellular component (MDmc); a centrally located parvocellular part (MDpc), which constitutes the major portion of this nucleus; and a lateral division in close proximity to the internal medullary lamina. According to its location, this division is called "paralaminar" (MDpl). It is also marked by alternating patterns of complementary fiber densities that traverse this portion of the MD, hence inspiring the term "multiformis" (MDmf). Some authors also distinguish MDpl and MDmf as two distinct entities (Jones 2007). The intralaminar nuclei are a number of cell groups situated within the internal medullary lamina that exhibit a common ontogenetic development. These nuclei can be identified employing immunohistochemical labeling (calbindin, calretinin, parvalbumin, and acetylcholinesterase). They can be subdivided into rostral, central, and caudal groups. The centromedian (CM) and parafascicular (Pf) nuclei are designated as the central or caudal group, depending on how many groups are differentiated. These 
nuclei are commonly viewed as a complex (CM/Pf). CM misses in some species, for instance, rodents. The central lateral (CL), paracentral (Pc), and central medial (CeM) nuclei are ascribed to the rostral group.

\section{Study design of reviewed literature}

Two general methods (i.e., anatomical and electrophysiological) have been widely used to uncover connectivity of projection systems. (1) Anatomical studies place lesions or tracers in the region of interest to label cell bodies, axons, and terminals (Morecraft et al. 2009). Most tracers prefer one direction of intracellular transport and either propagate towards the cell body (retrograde tracers, e.g., Fluoro-Gold) or towards the synapses (anterograde tracers, e.g., Phaseolus vulgaris-leucoagglutinin). Some tracers are bidirectional (e.g., wheat-germ agglutinin). A relatively recent development of this technique allows for labeling of multisynaptic connections via transneuronal tracers (e.g., rabies virus, HSV-1). Lesions show patterns of anterograde and retrograde degeneration, which can be labeled subsequently. Concerning the study design of anatomical studies, convergences were most commonly investigated interindividually. The comparison of projection territories was carried out by orientation via anatomical landmarks (e.g., cytoarchitectonics, stereotaxis). More convincing evidence can be found in intraindividual studies, in which several tracers are injected into different structures in the same animal. This approach allows for a direct comparison of the resulting labeling on the same or adjacent slices. These methods were most commonly combined with light microscopic analyses of the material. The limited resolution of light microscopy limits the power of evidence concerning the question of converging projections in regions in which projection territories come into close contact with each other, since synapses cannot be resolved. Relatively few studies employed electron microscopy to tackle this issue. Another limitation concerns the rate of tracer uptake into the neurons and the intracellular transport along the axon. Different tracers have been shown to have different sensitivities. This may explain some conflicting reports and might be indicative of an underestimation of projection territories in most anatomical studies. (2) Electrophysiological studies can reveal connectivity by stimulating one structure and measuring cell responses in another region using electrodes. By considering the approximate distance, the signal has to travel and the latency of the cell response, and one can determine whether a connection is monosynaptically activating postsynaptic ionotropic receptors (fast cell responses). Longer latencies might be caused by either oligosynaptic connections or slower cell responses elicited by intracellular signal cascades initiated by metabotropic receptors. Electrodes are usually placed using stereotactic coordinates and activity profiles that are specific for different regions. In extracellular single unit recording studies, electrodes are placed close to a neuron to measure its spiking behavior. A single unit is defined as a single firing neuron, whose spike potentials are distinctly isolated by a recording microelectrode. In intracellular single-unit studies, neurons are impaled by a microelectrode to measure the voltage change over time across the membrane during cell responses. This allows the spiking behavior of a neuron to be measured, as well as postsynaptic potentials that do not elicit an action potential. Accordingly, connections that do not elicit obvious changes in spiking behavior can also be revealed. In some studies, the exact localization of the investigated neurons is accurately determined by electrophoretic labeling or electrolytic lesions. Because these procedures are very intricate and time-consuming, sample sizes are often relatively small (Boulton et al. 1990).

\section{Main output structures and their terminal territories}

The cerebellum mediates the bulk of its output via the cerebellar nuclei, which lie deep in the cerebellar white matter (Asanuma et al. 1983a). Usually, four deep cerebellar nuclei (DCN) are distinguished: the dentate nucleus, which is situated laterally and is very large in primates; the medially situated fastigial nucleus; the interjacent interposed nuclei, which are distinguished by their relative position to each other; the anterior interposed (AIN); and posterior interposed (PIN) nuclei. The main cerebellar projection targets the VL. All DCN target this nucleus with different densities. At least in primates, the territories of the individual DCN are mainly segregated and display a somatotopic organization (Asanuma et al. 1983b). Further thalamic regions with cerebellar innervations are IL and MD. The basal ganglia structures are interconnected among each other and with other structures in a complex manner. Two grey matter regions constitute the main output structures and project mainly to the thalamus: GPi and SNr (Kuo and Carpenter 1973; Carpenter et al. 1976). In rodents, the entopeduncular nucleus is considered to be equivalent to the GPi and will hereafter be addressed as the GPi. The SNr mainly projects to VAmc, VLm, and MD (Carpenter et al. 1976) and, moreover, to the CM/Pf (Sidib et al. 2002). The GPi mainly projects to VL and VApc and in addition also to CM/Pf (Kuo and Carpenter 1973). The connections of the basal ganglia exhibit a topographical organization with motoric, associative, and limbic components (Ilinsky et al. 1985; Parent and Hazrati 1995a, b). 


\section{Evidence suggesting convergences}

\section{Rats, anatomical evidence}

Anatomical studies in rats repeatedly provided evidence for overlapping territories, although the extent was evaluated differently. Such overlapping territories can mainly be assumed in nuclei such as CL and Pf [please note that in rats, a CM is not described; (Faull and Carman 1978; Di Chiara et al. 1979; Haroian et al. 1981; Gerfen et al. 1982; Wiklund and Cuénod 1984; Cornwall and Phillipson 1988; Deniau et al. 1992)], in MDpl (Di Chiara et al. 1979; Haroian et al. 1981; Gerfen et al. 1982) and in VM (Faull and Carman 1968, 1978; Di Chiara et al. 1979; Herkenham and Nauta 1979; Kultas-Ilinsky et al. 1980; Gerfen et al. 1982; Deniau et al. 1992). Furthermore, interdigitating projections have been described in VA-VL. These are located in adjacent regions of cerebellar and pallidal territories (Deniau et al. 1992). Convergences in VA-VL are, therefore, likely to be limited to border regions of such interdigitations. Deniau et al. (1992) adopted a multitracer approach to investigate the relation of cerebellar and basal ganglia territories. They mainly found the territories to be segregated, but in VM and $\mathrm{Pf}$, these consistently overlapped. The cerebellar innervation of these nuclei was significantly less dense. Terminations seemed to occur via thin axon collaterals in an en passant fashion. Investigations of afferent projections to Pf (Cornwall and Phillipson 1988) and VM (Herkenham and Nauta 1979) employing retrograde tracers found labeled neurons mainly in GPi and SNr. In both instances, labeled neurons were also found in the DCN. Recent histochemical evidence supports the notion of complementary cerebellar and basal ganglial territories in that glutamate and GABA receptors were found in complementary densities in the thalamus (Kuramoto et al. 2010). The presented evidence suggests that territories of cerebellar and basal ganglia projections are mainly segregated in the rat thalamus. Regions of overlap (border regions of VA-VL, Pf, and VM) exhibit clear dominance of one projection system.

\section{Rats, electrophysiological evidence}

Evidence for converging projections of basal ganglia and cerebellum in rodents can be found in several electrophysiological studies (MacLeod et al. 1980; Chevalier and Deniau 1982; Buee et al. 1986; MacLeod and James 1984). MacLeod et al. (1980) placed stimulating electrodes in various areas and extracellularly recorded the spiking behavior in VM and Pf neurons. Stimulated regions included $\mathrm{SNr}$ and the contralateral superior cerebellar peduncle (brachium conjunctivum) — which carries the bulk of cerebellar efferents, including those to the thalamus. In this study, the brachium conjunctivum was stimulated to establish a stable activity in VM and Pf neurons, which otherwise exhibited a low level of spontaneous activity. Thus, the excitatory effect of cerebellar projections embodied the basis of observations made in this study. Under such conditions, intranigral applications of muscimol (GABA-agonist) led to a significant increase of spiking activity in $\mathrm{VM}$ and $\mathrm{Pf}$ neurons. Conversely, intranigral bicucullin (GABA-antagonist) increased nigral activity that inhibited the excitatory drive elicited by the superior cerebellar peduncle stimulation. A study with similar experimental design found very similar results (Buee et al. 1986). These studies, however, cannot determine whether such interactions are monosynaptic or mediated in other ways, such as local interneurons or alternative pathways (e.g., via superior colliculus). Other observations support the notion of monosynaptic convergences (MacLeod and James 1984): here, individual VM neurons were characterized by antidromical stimulations. Of 500 investigated VM neurons, approximately $72 \%$ were innervated by the DCN and exhibited an excitatory effect. Approximately $88 \%$ were innervated by $\mathrm{SNr}$ and exhibited an inhibitory effect. These observations suggest substantial convergences (at least 22\%) with significant physiological relevance in rat VM and most likely also Pf. VM neurons with cerebellar input displayed short latencies following stimulations in $\mathrm{SNr}$, reticular formation, superior colliculus, and frontal cortical areas. Confirmatory evidence was reported by Chevalier and Deniau (1982): in similar experiments with extracellular as well as intracellular recordings, they found converging inputs from $\mathrm{DCN}$ and $\mathrm{SNr}$ in $~ 58 \%$ of investigated neurons. The evidence presented above strongly suggests significant interactions of cerebellum and basal ganglia (i.e., SNr) in VM and Pf of rats. Regarding potential convergences of cerebellar and pallidal output, no studies in rats were found.

\section{Cats and dogs, anatomical evidence}

\section{VA-VL and VM}

In cats, territories of basal ganglia were found mainly anteriorly and laterally, whereas cerebellar territories were situated more posteriorly and medially. Pallidal and cerebellar territories interdigitated with minor overlaps (Ilinsky and Kultas-Ilinsky 1984). However, data from intraindividual tracing studies that pursue a multi-tracer approach are missing. In dogs, such techniques were employed to investigate the relation of cerebellar and nigral territories in the thalamus (Sakai and Patton 1993). The findings support the notion of interdigitating territories of cerebellar and basal ganglia projections with minor overlap in VA-VL of cats and dogs. Evidence for overlapping territories in the thalamus was provided by a retrograde tracing study in cats: 
Anderson and DeVito (1987) placed multiple very small tracer injections in different regions of VA-VL, VM, IL, and MDpl. They found the following patterns of retrogradely labeled neurons: (1) injections in dorsal parts of VL (VLd, $n=3$ ) labeled numerous neurons in DCN (338-1089 neurons), few-to-moderate amounts in GPi (2-318 neurons), and no-to-moderate amounts in $\mathrm{SNr}$ (0-102 neurons); (2) injections in caudal and caudolateral VL (VLc, $n=6)$ labeled few to moderate amounts of neurons in DCN (21-506 neurons), no-to-moderate amounts in GPi (0-94 neurons), and none up to few in $\mathrm{SNr}$ (0-2 neurons); (3) injections in $\mathrm{CL}$ and MDpl $(n=1)$ labeled few neurons in DCN (14 neurons), moderate amounts in GPi (116 neurons), and few in $\mathrm{SNr}$ (4 neurons); (4) injections in VM $(n=2)$ labeled few-tomoderate amounts of neurons in DCN (10-72 neurons), fewto-moderate amounts in GPi (9-86 neurons), and moderate amounts in $\mathrm{SNr}$ (82-107 neurons). We considered the relative frequencies of labeled neurons between these structures in selected experiments of this study to reveal the complementary relation of these projections in the different nuclei: (1) VLd: BG 0.28, DCN 0.72; (2) VLc: BG 0.21, DCN 0.79; (3) IL: BG 0.9, DCN 0.1; and (4) VM: BG 0.73, DCN 0.27 . These observations might be interpreted as evidence for overlapping territories with complementary projection densities. However, tracer placement in regions of interdigitating territories would label the projecting structures, even if no overlap was present. This especially concerns the injections into VLd and VLc. (Ilinsky and Kultas-Ilinsky 1984) describe the relationship of pallidal and cerebellar territories in an interindividual anterograde tracing study in cats as being complementary in the whole thalamus. However, they admit that a small zone of overlap in border regions of the territories cannot be ruled out by this evidence. Similar evidence was provided by another interindividual anterograde tracing study in cats with injections in DCN, GPi, and $\mathrm{SNr}$ (Hendry et al. 1979). It is worth mentioning that in this study, no projections of the DCN to VM were found, contradicting evidence from other studies in cats (Kultas-Ilinsky et al. 1978; Sugimoto et al. 1981; Anderson and DeVito 1987; Ilinsky and Kultas-Ilinsky 1984). In dogs, the VM was found to be a site of clearly overlapping cerebellar and nigral territories [see Fig. 4 in Sakai and Patton (1993)]. Furthermore, it was identified as being the main territory of fastigial projections in dogs (Person et al. 1986; Sugimoto et al. 1981; Jimenez-Castellanos and Reinoso-Su rez 1985). One could hypothesize that these inconsistencies might be due to an incomplete coverage of the DCN, differences in nomenclature or interspecies differences in dogs and cats. Indeed, the fastigial nucleus has been neglected in some studies without addressing this issue sufficiently (Ilinsky and Kultas-Ilinsky 1984). Other studies did not show the injection sites (Hendry et al. 1979). Thus, it is not clear to what extent the discrepancy between observations can be attributed to an omission of the fastigial nucleus. For a detailed discussion, see the section, "Interspecies differences-VM".

\section{IL and MD}

In an interindividual anterograde tracing study with injections in $\mathrm{SNr}, \mathrm{GPi}$, and $\mathrm{DCN}$, nigral projections to $\mathrm{CL}, \mathrm{Pc}$, and $\mathrm{CeM}$ and pallidal projections to $\mathrm{CM}$ were found to be clearly overlapping with cerebellar projections (Hendry et al. 1979). We propose a potential involvement of MDpl as well, based on reevaluations of the presented figures and the consideration of the difficult distinction between CL and MDpl [(Hendry et al. 1979), please see also Figs. 1, 2 and 3 in Mai and Forutan (2012)]. Retrograde tracing studies in CM/Pf (Royce et al. 1991), Pc, and CL (Anderson and DeVito 1987; Niimi et al. 1990), as well as MD (Ono and Niimi 1986; Anderson and DeVito 1987) support these observations. Projections arising from $\mathrm{SNr}$ and GPi were always found to be stronger than those from the cerebellum. This suggests a complementary projection pattern of cerebellar and basal ganglia structures. Furthermore, cerebellar projections seem to invade basal ganglia territories rather than reversed, possibly indicating a cerebellar modulation of restricted regions of basal ganglia territories in the thalamus. Some authors express doubt concerning the labeling in $\mathrm{CM}$ and argue that these might represent passing fibers rather than terminating projections (Carpenter et al. 1958; McMasters and Russell 1958; Sugimoto et al. 1981; Ono and Niimi 1986; Ilinsky and Kultas-Ilinsky 1984). Based on this interpretation, these authors conclude that territories of cerebellum and basal ganglia are also segregated in the IL. In contrast, retrograde tracing studies are indicative that terminations do exist. It is conceivable that axons emit collaterals during their course through the CM/Pf. Such collaterals of pallidal projections terminating in the $\mathrm{CM} / \mathrm{Pf}$ have been shown in intracellular tracings (Arecchi-Bouchhioua et al. 1997). Furthermore, en passant contacts could exist (Sakai et al. 1996). It is possible that certain anterograde tracers employed are not sufficiently sensitive to reveal such filigree structures. Various tracer substances do differ substantially in this regard (Royce et al. 1991). Since the presented anterograde investigations were conducted inter-individually, and no intra-individual comparison via multi tracer approach is available, it is not possible to reach a final conclusion regarding the existence of overlap in MD and IL of cats. Morphological studies in cats (Yamamoto et al. 1985; Tseng and Royce 1986) and primates (Pearson et al. 1984) indicate that a subpopulation of IL neurons-especially in CM/Pf-have dendrites with up to $1 \mathrm{~mm}$ length (Tseng and Royce 1986). This circumstance increases the likelihood of converging signals in this region. In dogs, cerebellar projections to CM/Pf and posterior parts of MD have been described (Person et al. 1986; Sakai and Patton 1993). It is unclear if such conflicting observations 


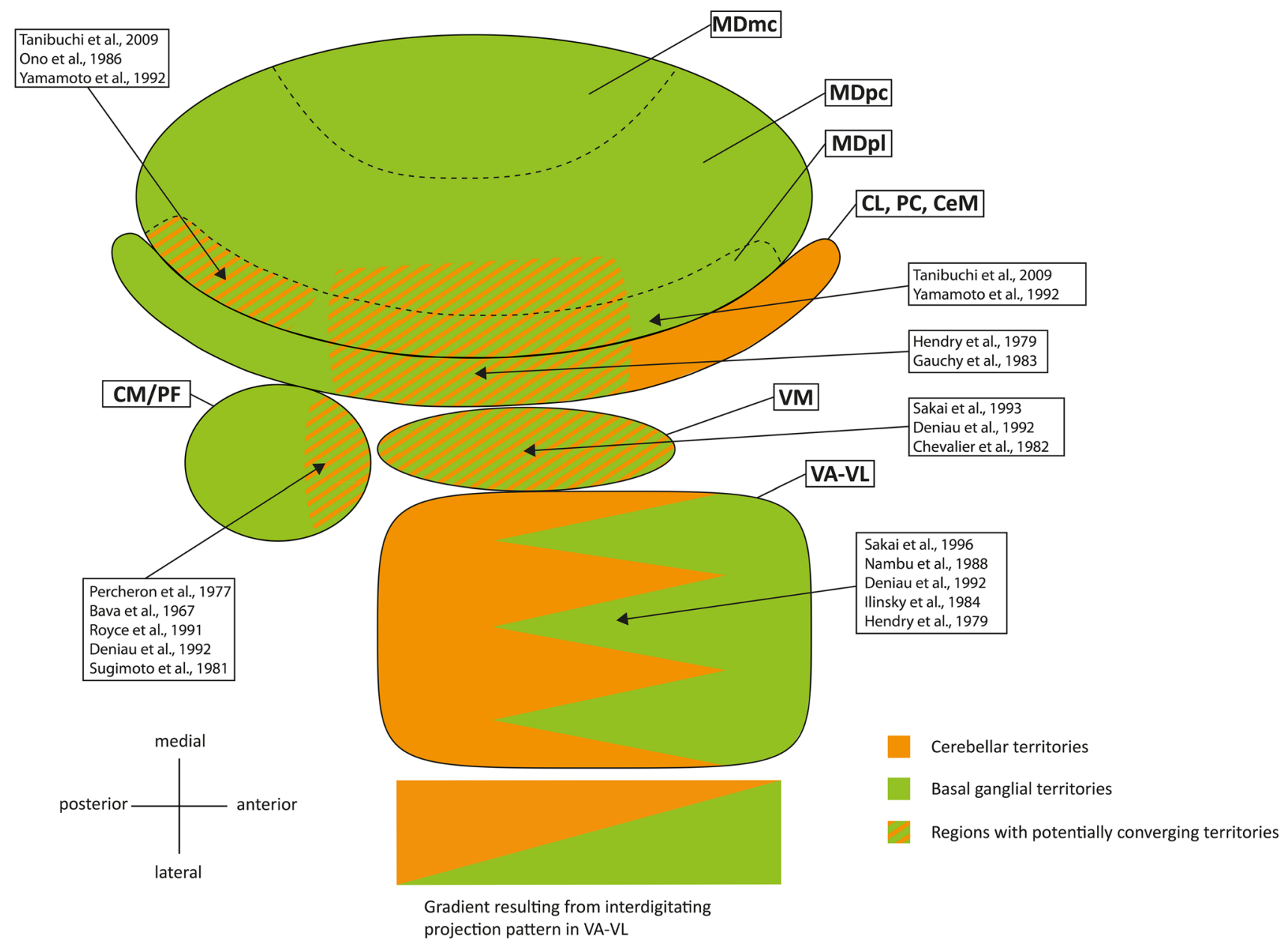

Fig. 3 Relation of projections from cerebellum and basal ganglia in the thalamus. In this schematic, we summarize the relation of the projection territories of cerebellum and basal ganglia to each other. Cerebellar territories are colored orange, basal ganglia ones green and regions with potentially converging territories are indicated by

are due to interspecies differences or methodological limitations. An evaluation of this question is impeded by a very limited number of studies in dogs. Evidence suggests mainly segregated territories of cerebellar, nigral, and pallidal projections in VA-VL of cats. Overlap, if any, was only found in adjacent border regions of the territories. In dogs, VM is highly likely to be a site of convergence of nigral and cerebellar projections. Evidence in cats does not support this observation, although this might be due to methodological issues. The IL and MDpl of cats are consistently described as being regions of overlapping territories of cerebellar and basal ganglial projections. Projections arising from $\mathrm{SNr}$ and GPi were always found to be stronger than those from the cerebellum. Data in dogs are very limited. fasciated patterns. The interdigitating projection territories in VAVL lead to the anteroposterior density gradient described by Sakai (1996). Interspecies differences as well as projection densities are not accounted for in this schematic

\section{Cats and dogs, electrophysiological evidence}

Two of the electrophysiological studies in cats reviewed here did not find any evidence for converging projections of basal ganglia and cerebellum on thalamic neurons (Ueki 1983; Ueki et al. 1977). Stimulating electrodes were placed bilaterally in the superior cerebellar peduncle as well as unilaterally in GPi and/or SNr. Several electrodes were placed in $\mathrm{SNr}$ and GPi to optimize coverage. In this way, 75 (Ueki et al. 1977) and 42 (Ueki 1983) VA-VL and VM neurons were recorded in several animals. Neurons with monosynaptic cerebellar input were frequently found to be interdigitating with ones that received monosynaptic pallidal or nigral input. Since in these studies, the sample sizes were relatively small-especially when considering the size of the investigated regions-it cannot be excluded that convergences were simply overlooked. A number of studies in cats contradict 
these findings and report convergences with varying degrees (Desiraju and Purpura 1969; Uno and Yoshida 1975; Deniau et al. 1978; Uno et al. 1978; Yamamoto et al. 1984; Gazzara et al. 1986). These studies also focus on VA-VL and VM. In two studies with similar experimental design, Uno and colleagues found monosynaptic convergences in $\sim 5.6 \%$ $(n=89)$ and $\sim 3.7 \%(n=218)$ of investigated neurons in border regions of pallidal and cerebellar territories in VA-VL (Uno and Yoshida 1975; Uno et al. 1978). They unilaterally stimulated GPi with six electrodes and the superior cerebellar peduncle bilaterally with two electrodes; recordings were conducted throughout VA-VL. Similar results were found by Yamamoto et al. (1984) in investigations of VA-VL as well as VM $(\sim 3.7 \% ; n=163)$. In addition, Gazzara et al. (1986) reported a similar relation $(\sim 3 \%, n=32)$. The latter study also quantified convergences with longer latencies, which were found substantially more often $(\sim 53 \% ; n=32)$. Long latencies were interpreted to represent oligosynaptic connections. Another study reported markedly larger numbers of monosynaptic convergences in VL $(\sim 20 \% ; n=60)$ and convergences with longer latencies were found "in a somewhat larger portion of VL neurons" (Desiraju and Purpura 1969). Longer latencies were also interpreted as oligosynaptic connections. We propose to also consider the possibility that such longer latencies might occur due to intracellular signal cascades mediated by G-proteincoupled receptors. Furthermore, it cannot be excluded that glutamate is released via volume transmission or spillover, diffusing to and activating nearby synapses (Agnati et al. 2010; Okubo and Iino 2011); for discussion see the section, "physiological relevance". Two of the studies reviewed here addressed nigral and cerebellar convergences. One did not find any convergences (Ueki 1983), which is in stark contrast to observations reported by Deniau et al. (1978). They found approximately $27 \%(n=\sim 100)$ of relay neurons in VL to receive monosynaptic input both from DCN and SNr. No studies were found in either cats or dogs that investigated convergences in IL or MD. However, stimulations of the fastigial nucleus have been shown to elicit spiking activity in CM/Pf (Bava et al. 1967). Approximately 69\% of investigated neurons that exhibited spontaneous activity exhibited such responses. Convergence of pallidal and cerebellar projections on neurons of VA-VL and VM in cats has been shown repeatedly, albeit with notably differing degrees; convergences of nigral with cerebellar projections have been shown but are controversial. Convergences in MD and IL have not been shown, but some data indicate that such convergences are likely to exist in CM/Pf. Equivalent electrophysiological data in the dog are virtually missing.

\section{Primates, anatomical evidence}

\section{VA-VL}

Sakai et al. (1996) compared cerebellothalamic and pallidothalamic projections in macaca fuscata by injecting two anterograde tracers simultaneously in the same individual. These were subsequently labeled in the same section, which allows for a direct comparison of terminal territories. Large injections in DCN and GPi revealed three general patterns of labeling. First, dense pallidal labeling was found in VApc and VLo, whereas dense cerebellar labeling was situated in VPLo and X. Second, interdigitating patterns of cerebellar and pallidal labeling were found in the transitional zones of both territories. Third, the density of labeling displayed a complementary anteroposterior gradient [see Fig. 5, left in Sakai et al. (1996)]. Overlap was observed occasionally, but interdigitations that indicated segregated territories predominated. Because such interdigitations were found frequently, the question arises whether dendrites of thalamic neurons in those border zones invade both territories. The functional significance of these interdigitations is entirely unknown. Supporting evidence was reported in an earlier study that also described an anteroposterior gradient of pallidal and cerebellar territories. They also employed two tracers in the same individual to compare these territories, but tracers were labeled on successive slices, providing slightly less reliable data. The extent of overlap in VA-VL was estimated at approximately $2.5 \mathrm{~mm}^{2}$ [see Fig. $15 \mathrm{E}$ in Rouiller et al. (1994)]. This evidence is contrasted by a number of interindividual comparisons-employing a single tracer substance - concluding that the territories of basal ganglia and cerebellum are segregated (Kuo and Carpenter 1973; Asanuma et al. 1983a; Schell and Strick 1984; Ilinsky and Kultas-Ilinsky 1987; Percheron et al. 1996): Percheron et al. (1996) investigated thalamic projection territories by injecting an anterograde tracer into $\mathrm{DCN}, \mathrm{GPi}$, and $\mathrm{SNr}$; intersubject comparisons of territories were carried out using stereotactic orientation techniques. Intersubject variabilities cannot be accounted for in this manner. Other studies with similar experimental design used cytoarchitectonic landmarks as a tool for intersubject territory comparison (Nauta and Mehler 1966; Kuo and Carpenter 1973; Carpenter et al. 1976; Kim et al. 1976; Stanton 1980; Kalil 1981; Asanuma et al. 1983a; Ilinsky and Kultas-Ilinsky 1987; Schell and Strick 1984). These studies distinguished a "cell sparse zone" (X, VPLo, and VLc) from other regions of VA-VL with higher cell densities (especially VLo). The cell sparse zone was defined as the cerebellar territory and was used as a landmark to compare pallidal and cerebellar territories. Regarding this approach of orientation, Sakai et al. (1996) emphasized that they didn't find such a clear association of territories to the cytoarchitectonic landscape. This view is 
reinforced by findings in electrophysiological investigations (Nambu et al. 1988). Hence, the interindividual comparison of territories by means of stereotactic as well as cytoarchitectonic orientation might have led to underestimations of overlap in these studies. Moreover, careful inspection of the pictorial material provided by Percheron et al. (1996) also indicates overlap-especially in border regions of cerebellar and pallidal territories [please see Fig. 16 in Percheron et al. (1996)].

\section{VLm}

Anterograde tracing studies reported nigral (Carpenter et al. 1976) and pallidal (Kuo and Carpenter 1973; Inase and Tanji 1995) efferents to VLm; cerebellar fibers mainly traverse this nucleus, terminations are less obvious (Stanton 1980; Kalil 1981; Sakai et al. 1996). If territories of cerebellar and basal ganglia projections overlap in this nucleus, these are likely to be sparse. This is peculiar, since in rats, cats, and dogs, $\mathrm{VM}$ is a conspicuous candidate to be a site of convergence of cerebellar and basal ganglial territories. This discrepancy will be discussed in detail in the "Interspecies differences".

\section{IL and MD}

Pallidal and nigral projections to primate $\mathrm{CM} / \mathrm{Pf}$ are well known (Sidibé et al. 1997; Sidib et al. 2002; Parent et al. 1983). Labeling of cerebellar axons in CM/Pf was described to be mainly fibers of passage on their way to CL (Kalil 1981; Ilinsky and Kultas-Ilinsky 1987). Some authors also consider the possibility of some cerebellar terminations, although sparse (Kusama et al. 1971; Sakai et al. 1996, 2000; Rouiller et al. 1994; Chan-Palay 1977; Percheron 1977). Electronmicroscopic investigations of CM following lesions in the DCN did not find any degenerated terminals (Harding 1973). Cerebellar projections to CL were frequently shown (Kalil 1981; Asanuma et al. 1983a; Ilinsky and Kultas-Ilinsky 1987; Percheron et al. 1996), terminating in "patchy clusters" (Sakai et al. 1996). Admittedly, no study in primates reported projections of the basal ganglia to that nucleus. However, a number of anterograde tracing studies reported nigral terminals in the adjacent MDpl (Carpenter et al. 1976; Ilinsky et al. 1985; Percheron et al. 1996; Sidib et al. 2002). The differentiation of MDpl and CL has been assessed to be very difficult (Jones 2007; Mai and Forutan 2012). Furthermore, cerebellar projections to MDpl were also found (Ilinsky and Kultas-Ilinsky 1987; Yamamoto et al. 1992; Sakai et al. 1996). Some overlap in the region of CL and MDpl is, therefore, likely. Although a numerous amount of studies postulate a strong segregation of the BG and cerebellar system, some studies have found existing interdigitating patterns, indicating a potential informational exchange between these two systems; on a closer look, even some studies have demonstrated overlap regions of pallidal and cerebellar projections; this was specifically located in border regions between both territories.

\section{Primates, electrophysiological evidence}

Electrophysiological investigations regarding convergences of cerebellar and pallidal projections to the thalamus focused on the motor thalamus (VA-VL). Some studies found neurons with converging input, albeit very few [between $\sim 0.5 \%$, $n=180$ and $~ 3.4 \%, n=86$; Yamamoto et al. (1983); Nambu et al. (1988); Jinnai et al. (1993)]. In these studies, stimulations covered the DCN and GPi as much as possible. Multiple neurons were recorded along the electrode track through various regions of VA-VL and tested for monosynaptic responsiveness following GPi and DCN stimulation. Two studies did not find any neurons with converging input (Anderson and Turner 1991; Buford et al. 1996). Anderson and Turner (1991) confined the stimulated regions in GPi and superior cerebellar peduncle to those that were involved in arm movements. An observation in this study that conflicts with common findings was the very small number of neurons receiving pallidal input in relation with those with cerebellar input. In addition, Buford et al. (1996) focused on regions that are associated with arm movements. They stimulated regions in GPi and VA-VL, aiming to distinguish cerebellar and pallidal territories based on their "micro excitability", i.e., eliciting an arm movement following a stimulus. Micro-excitable regions were assumed to be cerebellar territories. Indeed, an injection of a retrograde tracer into a micro-excitable region that was directly adjacent to a region with pallidal input (border region of VLc and VLo) did label neurons in DCN but not GPi. This evidence rather supports the notion that the interdigitating projection pattern in VA-VL resembles segregated territories. Regions for which anatomical evidence of cerebellar interactions with nigral projections exists (especially MDpl and surrounding regions) have not yet been examined with electrophysiological methods. One study found that nigral stimulation elicited spiking behavior in lateral and paralaminar regions of MD (Tanibuchi et al. 2009). Convergences with cerebellar input to this area, therefore, seem likely.

\section{Interspecies differences}

Observations regarding the question as to whether thalamic efferents of the main basal ganglia output structures (GPi/ $\mathrm{SNr}$ ) converge with cerebellar output mediated by the DCN are partially conflicting. 


\section{VA-VL and VM}

Projections from cerebellum and basal ganglia to VA-VL were found to be mainly segregated in rats, cats, dogs as well as primates. Comparisons of pallidal and cerebellar territories in primates employing anterograde tracing techniques revealed a complementary anteroposterior density gradient and interdigitating projection patterns [Fig. 2 and 6; Rouiller et al. (1994); Sakai et al. 1996]. Such interdigitations were also found in cats (Ilinsky and Kultas-Ilinsky 1984), dogs (Sakai and Patton 1993), and rats (Deniau et al. 1992). These observations indicate a consistency of this organizational principle in VA-VL across different taxonomical orders. It is controversial which regions in the primate thalamus correspond to the VM of rats, cats, and dogs (Jones 2007). Some authors designated VM to the "unspecific" nuclei and, therefore, being related to the intralaminar nuclei, because it diffusely projects to lamina I of large portions of the cerebral cortex (Krettek and Price 1977; Herkenham and Nauta 1979). In primates, VLm was proposed as being its equivalent (Olszewski 1952), other authors assigned it to a rostral nucleus (Percheron et al. 1996), medial portions of VA (Paxinos et al. 1999), or VP (Jones 2007). We assume that medial portions of VL (VLm) in primates represent the interspecies equivalent of the rat VM. No electrophysiological study in primates found convergences in that region that exhibited a greater extent than was found in the remaining VA-VL [ $<4 \%$; Uno and Yoshida (1975); Yamamoto et al. (1983); Nambu et al. (1988); Anderson and Turner (1991); Jinnai et al. (1993); Buford et al. (1996)]. In addition, anatomical studies employing tracing techniques did not provide any evidence of substantial overlap in VLm. Contrasting observations were made in the rat VM, revealing notable overlap of cerebellar and nigral territories (Faull and Carman 1968; Di Chiara et al. 1979; Herkenham and Nauta 1979; Kultas-Ilinsky et al. 1980; Gerfen et al. 1982; Deniau et al. 1992). Nigral projections dominated this nucleus, whereas cerebellar fibers were found to be thinner and less dense. Electrophysiological studies support these findings (MacLeod et al. 1980; Chevalier and Deniau 1982; Buee et al. 1986; MacLeod and James 1984). Evidence from anatomical studies in dogs forms a similar picture (Person et al. 1986; Sakai and Patton 1993). In cats, anatomical as well as electrophysiological evidence is heterogeneous, but rather suggests limited convergences comparable to ratios in primates (Hendry et al. 1979; Anderson and DeVito 1987; Desiraju and Purpura 1969; Chevalier and Deniau 1982; Yamamoto et al. 1984; Gazzara et al. 1986; Ilinsky and Kultas-Ilinsky 1984). On the basis of the existing studies, we assume that the amount of convergences in VA-VL has diminished from rodents $>$ carnivores $>$ primates. Because intraorder variabilities do exist, one should be careful to extrapolate findings concerning the amount of convergences in one representative of a taxonomic order to another (e.g., macaca to human). The available evidence is not sufficient to draw a final conclusion in this matter: in rats, no electrophysiological studies examining pallidal and cerebellar interactions were conducted; investigations in mice seem to be completely missing and would be valuable to allow for further comparison of species within one taxonomic order; in cats, studies employing multiple tracers to intraindividually compare terminal territories are missing; electrophysiological evidence is missing in dogs; in primates, and electrophysiological evidence should be extended, especially concerning nigral and cerebellar interactions in the VA-VL.

\section{IL}

Besides the anterior group (CL, $\mathrm{Pc}$, and $\mathrm{CeM})$, this particularly holds for the caudal group (CM/Pf). Cerebellar projections to the anterior group have frequently been shown in rats (Faull and Carman 1978; Haroian et al. 1981), cats (Hendry et al. 1979; Anderson and DeVito 1987; Niimi et al. 1990), dogs (Person et al. 1986; Sakai and Patton 1993), and primates (Kalil 1981; Asanuma et al. 1983a; Ilinsky and Kultas-Ilinsky 1987; Percheron et al. 1996). Indications of nigral projections to this region can be found in rats (Gerfen et al. 1982), cats (Hendry et al. 1979; Anderson and DeVito 1987; Niimi et al. 1990), and dogs (Sakai and Patton 1993), but not in primates. It is possible that missing observations of such projections in primates can be ascribed to the difficult differentiation of CL and MDpl (Jones 2007; Mai and Forutan 2012). Nigral and cerebellar projections to the primate $\mathrm{MDpl}$ are well described (see below). In cats and primates, studies employing multiple tracers and electrophysiological techniques to determine cerebellar and nigral territories in the same animal are missing. Indications of convergence in the rat Pf can be frequently found in anatomical (Faull and Carman 1978; Di Chiara et al. 1979; Haroian et al. 1981; Deniau et al. 1992; Gerfen et al. 1982; Wiklund and Cuénod 1984; Cornwall and Phillipson 1988) and electrophysiological studies (MacLeod et al. 1980; MacLeod and James 1984). In cats (Carpenter et al. 1958; McMasters and Russell 1958; Hendry et al. 1979; Sugimoto et al. 1981; Royce et al. 1991; Ilinsky and Kultas-Ilinsky 1984) and primates (Kusama et al. 1971; Chan-Palay 1977; Percheron 1977; Rouiller et al. 1994; Sakai et al. 1996, 2000), similar evidence points towards CM. Since no CM is defined in rats, such observations indicate that Pf constitutes equivalent connectivities and functions. Some studies in cats, however, reported cellular responses in this region that were elicited by cerebellar (Bava et al. 1967, 1979) and nigral (Gauchy et al. 1983; Miyamoto and Jinnai 1994) stimulation. 


\section{MD}

In all species included in this review, convergences of cerebellar and nigral projections were likely to be found in lateral regions of MD (MDpl, MDmf, and MDpc). Anatomical studies in rats (Haroian et al. 1981; Gerfen et al. 1982), cats (Ono and Niimi 1986), dogs (Person et al. 1986), and primates (Carpenter et al. 1976; Stanton 1980; Asanuma et al. 1983a; Ilinsky et al. 1985; Ilinsky and Kultas-Ilinsky 1987; Yamamoto et al. 1992; Percheron et al. 1996) provide evidence that indicates substantial projections arising from these structures. In cats, these projections were described to be arranged in a complementary fashion with cerebellar projections being located posteriorly and those arising from $\mathrm{SNr}$ anteriorly (Ono and Niimi 1986). In primates, such an arrangement was not described (Yamamoto et al. 1992; Tanibuchi et al. 2009). Further indications suggesting convergence exist when considering the difficult differentiation of MDpl and CL (Jones 2007; Mai and Forutan 2012). In this way, conflicting reports from electrophysiological studies might be explained that found neuronal responses in CL but not MD following stimulations of the fastigial nucleus (Bava et al. 1967). The frequently described cerebellar projections to CL very likely also invade the MDpl (Person et al. 1986). The nigral territory in MD was recently described employing electrophysiological techniques (Tanibuchi et al. 2009). Investigations specifically exploring potential interactions of $\mathrm{SNr}$ and DCN in the MD are lacking in all animals included in this review.

\section{Studies in the human species}

As in vivo tracer studies are not applicable in humans, evidence on thalamic interconnectivity with the cerebellum and basal ganglia in humans is rather sparse. Few studies either relate to either postmortem studies or MRI-based diffusion tractography.

An influencial postmortem study in the human brain regarding cerebello- and basal ganglia-thalamic projections is reported by Gallay et al. (2008). Using multiple immunohistochemical staining procedures, these authors demonstrate that the majority of the cerebellothalamic and pallidothalamic tracts are clearly separated relative to their thalamic entrance; yet, exchanges between the two fiber systems could not be completely excluded. At subthalamic level, however, evidence for a clearer separation between the two tracts was apparent. At thalamic level, Kultas-Ilinsky et al. (2011) recently also provided data on basis of GAD65 immunoreactivity for GABAergic nigro- and pallido-thalamic as well as cerebellar afferent territories in different motor nuclei of the human thalamus; in principle, the gross distribution pattern of GAD65 was similar in human thalami to those in resus monkeys. This view, however, has been challenged by multiple studies in non-human primates (see above): evidence for a convergence of pallido- and cerebello-thalamic fibers in the same thalamic nuclei on basis of anatomical tracing has been demonstrated only by experimental studies in monkeys yet (Rouiller et al. 1994; Sakai et al. 1996; Sakai et al. 1999, 2000). Whether this incongruence is due to methodological limitation of post-mortem studies (e.g., Schmierer et al. 2010; Stüber et al. 2014; van Duijn et al. 2011), or indeed, a divergence in the organization in the human brain has to be investigated by alternative approaches.

Diffusion MRI and tractography provides such an alternative, yet less well validated method to identifying anatomical connections in the living human brain (for further detail and a discussion on limitations, see Jbabdi et al. 2015; Lerch et al. 2017). Briefly, in the analysis of connectivity distributions, two different approaches can be taken: (1) tractography-based parcellation as recently shown for the thalamic connections with the cerebellum and basal ganglia in (Lambert et al. 2016) or (2) characterization of projections and atlas-based assessment of connectivity fingerprints per thalamic regions as recently demonstrated by our group (Pelzer et al. 2017).

Parcellation approaches as those applied by Lambert et al. (2016) have the inherent limitation of grouping connections into segregated subdivisions (according to the principle "the winner takes it all"): Putative regions of convergence cannot be deduced from this. The authors report cerebellar connections in the posterior-anterior group (consisting of lateral posterior nucleus and medial pulvinar) and the ventrolateral thalamic group. Connections of the thalamus with the basal ganglia were associated with the mediodorsal group and the ventroanterior group. Cerebellar connections to the thalamus, however, did not exhibit the typical fiber crossing at the decussation of the superior cerebellar peduncle, which is not in line with the actual anatomical literature and calls validity into question [see Fig. 6h in Lambert et al. (2016)].

Conversely, we (Pelzer et al. 2017) demonstrated a decreasing anterior-to-posterior gradient for pallido-thalamic connections in: (1) the ventral-anterior thalamus; (2) the intralaminar nuclei; and (3) midline regions. Moreover, we presented evidence for a decreasing posterior-to-anterior gradient for dentato-thalamic projections predominantly in: (1) the ventral-lateral and posterior nucleus; (2) dorsal parts of the intralaminar nuclei and the subparafascicular nucleus, and (3) the medioventral and lateral mediodorsal nucleus. By our approach, a considerable overlap of connectivity pattern between basal ganglia and cerebellum was apparent in intralaminar nuclei and midline regions. Yet, also here, results need to be carefully considered with uncertainty due to limitations of the applied technique, diffusion tractography: the approach cannot, by principle, differentiate 
converging synapses from interdigitating projection patterns, and it does neither lead to discriminate direction of information transfer nor to determine an axonal termination. Still, it greatly holds promise to define thalamic territories that are likely for projection overlaps.

Nevertheless, next to putatively overlapping regions, however, also direct communication in the human brain between basal ganglia and cerebellum, via the internal part of the pallidum, has been described by (Milardi et al. 2016; Pelzer et al. 2013), which is in accordance with transneuronal tracing studies in nonhuman primate studies (Hoshi et al. 2005).

\section{Organizational principles of territories}

The key results of our extensive literature research are summed up in Fig. 3. Based on our detailed inspection of the enlisted studies above, we propose two different organization principles: (1) a network specific convergence and (2) a "core and shell" projection.

\section{Network-specific convergences}

Network-specific convergence is a general principal in information transfer; here, only one "pipe" is used to deliver all forms of communication. This means that all neurons that are involved in, e.g., the oculomotor network project to one "pipe" that initiates, for example, the movement of the eye. There is evidence to suggest that the oculomotor network receives substantial converging input from cerebellum and basal ganglia. Such a network comprises structures of the brainstem (reticular formation, superior colliculus, and red nucleus), thalamus (CM/Pf, MD), basal ganglia, and cortex (frontal eye fields). Nigral and cerebellar projections have been shown to converge on neurons of the superior colliculus in the rat (Westby et al. 1994). Similarly, these two structures seem to interact in the reticular formation (ShammahLagnado et al. 1983, 1987, 1992; Schneider et al. 1985) and the nucleus of Darkschewitsch, which has been associated with the red nucleus based on its similar connectivity patterns (Onodera and Hicks 2009, 1995, 1998). The involved nuclei in the thalamus - that is, MDpl and CM/Pf-receive input from all structures mentioned here in the context of the assumed oculomotor network (Ono and Niimi 1986; Royce et al. 1991; MacLeod and James 1984) and project to the frontal eye fields (Sadikot and Rymar 2009; Tanaka and Kunimatsu 2011). Furthermore, monosynaptic projections arising in SN pars compacta and the ventral tegmental area have been shown to project to the vermis of the cerebellum, which is associated with oculomotor function (Ikai et al. 1992; Melchitzky 2000). Another potential network receiving converging inputs on a subcortical level might be associated with facial movements (Bava et al. 1979; Pong et al. 2008).

\section{“Core and shell" organization}

Another discussable idea is the one of a "core and shell" projection pattern. Years ago, Berkley (1983) introduced this idea for the thalamic region VPL; this region could not be sharply separated from each other or from more rostral regions by their pattern of afferent input, their efferent output or their cytoarchitecture; he defined it as consisting of (1) an inner "core" that receives dense afferents that exclusively arise from one projection system and (2) an outer "shell" that is characterized by decreasing projection densities and an intermingling with afferents of other projection systems [see Fig. 6 in Berkley (1983)]. A "core and shell” organization seems to be present in cerebellar and pallidal projection territories in VA-VL: regions with high projection densities that are virtually exclusive to one projection system are found in the bigger parts of VA (pallidal) and VL (cerebellar). An anteroposterior density gradient has been described that suggests a successive blending of cerebellar and pallidal territories. This blending is characterized by interdigitating projection patterns that only overlap sparsely in adjacent border regions [Fig. 1 B/C; Sakai et al. (1996); Rouiller et al. (1994)]. Such observations support the notion of a "core and shell" organization of these output systems of basal ganglia and cerebellum.

\section{Extrathalamic cerebello-BG communication}

Next to the described "network specific convergence" and "core and shell" organization principle, which may exist inside the thalamus, it has to be considered that also extrathalamic regions with cerebellar and basal ganglia projections may be part of a subcortical communication. To this end, one imminent region is the subthalamic region, which embraces the subthalamic nucleus, zona incerta, Forel's fields $(\mathrm{H}, \mathrm{H} 1$, and H2) and their nucleus (McKenzie 2009). Both, the cerebellum and the basal ganglia, project to this subthalamic region. For the subthalamic nucleus, recent findings reveal the existence of an anatomical substrate for the bidirectional communication between cerebellum and basal ganglia, as shown in rats (Ichinohe et al. 2000) and monkeys (Bostan et al. 2010, 2013; Bostan and Strick 2010) sending disynaptic projections to the cerebellar cortex by way of the pontine nuclei. Similar evidence has been recently reported in the human brain (Pelzer et al. 2013; Milardi et al. 2016), consciously that these techniques are not able to dissolve direct synaptic relay. Next to a direct basal ganglia-cerebellar communication, the dentate nucleus sends efferent projections 
to the subthalamic region via red nucleus. In the rostral part of the red nucleus, a large bundle of fibers turns dorso-rostrally away from the ascending limb of the crossed superior cerebellar peduncle. The bundle sends some fibers to the external lamina of the thalamus and the rest traverse the centrum medianum and parafascicular nucleus to continue in the internal lamina of the thalamus. Further rostrally, another large bundle turns away from the ascending limb; these traverses the prerubral field and Forel's field (H1). The fibers from the dentate nucleus pass the dorsal part of the red nucleus, reach the pre-rubral field, and enter the ventral part of the VL nucleus of the thalamus, and finally terminate in the ventral anterior nucleus (VA). A small fascicle of fibers leaves the field of Forel and passes laterally into this nucleus and the zona incerta [page 299 and ff in Chan-Palay (1977)]. In addition, the interposite nucleus (Plaha et al. 2008) and the basal ganglia (Chivileva and Gorbachevskaya 2008) project to the zona incerta making a subcortical communication between the cerebellum and the basal ganglia highly probable. For the dentate nucleus, a direct communication between this nucleus and the pallidum has been described (Hoshi et al. 2005).

\section{Physiological relevance}

The physiological relevance of subcortical interactions of basal ganglia and cerebellum is mostly unknown and has not been addressed as yet. In the light of the studies presented in this review, the question arises whether the observed convergences represent casual overlaps of territories in the sense of a "core-shell" principle (Berkley 1983) or if they represent distinct functional networks that differ in their mode of information processing from such networks without convergences, as mentioned above. Considering their limited occurrence in the thalamus, the functional impact might indeed be vanishingly low. We propose that this connectivity pattern might be of physiological significance if it is a distinct property of specific functional networks as proposed above. Assuming that convergences are specific to certain functional networks (as described in the networkspecific convergences), it is likely that signal processing in networks with convergences in the thalamus substantially differs from such without convergences. One conceivable function of convergences could be a competitive gating mechanism. Here, inhibitory and excitatory signals from basal ganglia and cerebellum would be integrated in thalamic projection neurons, which would convey the results of that computation to the cortex. Since projection densities were found to be complementary in regions of overlap, such a scenario seems to be less likely. A modulation of the excitability of thalamic projection neurons seems more suitable to the available data. One transmitter that influences the excitability of the two systems is glutamate. This transmitter is well known to have neuromodulatory functions that are conveyed via metabotropic glutamate receptors (Bonsi et al. 2005). These trigger intracellular signal cascades that can have various effects on the responsiveness of a neuron (Platt 2007). Such effects take longer to reach full effect than ligand-gated ion channels. This coincides with observations from several studies that report converging inputs with longer latencies and complex neuronal response patterns (Desiraju and Purpura 1969; Gazzara et al. 1986; Deniau et al. 1992; Sakai et al. 1996, 2000; Buford et al. 1996). In these studies, longer latencies were interpreted as oligosynaptic connections. Such indirect interactions might be mediated by local interneurons, intrathalamic circuitries (e.g., IL or reticular thalamic nucleus), or cerebral cortex (Niimi et al. 1990). The impact of such neuromodulation might be increased by volume transmission or spill-over effects. By such means, the neuromodulatory substance diffuses from the location of release to nearby receptors that are not necessarily strictly related to a synapse. Such modi of transmitter release have been shown for glutamate (Agnati et al. 2010; Okubo and Iino 2011). Observations of en passant varicosities in cerebellar projection territories further support this notion (Sakai et al. 1996; Deniau et al. 1992). In this way, sparse and diffuse projections might also exert a substantial influence on a terminal territory. In addition, the interdigitating projections in VA-VL might be related in such a fashion. Reports of longer latencies and substantial convergences in this region support this supposition (Desiraju and Purpura 1969; Deniau et al. 1978; Gazzara et al. 1986). Assuming the existence of a trend of decreasing subcortical convergences-as described in the section, "Interspecies differences", one could infer that the interaction of basal ganglia and cerebellum was progressively translocated to the cerebral cortex during brain development. This might have led to enhanced flexibility of the organism's behavior. Conversely, pronounced convergences on thalamic levels might facilitate faster and more robust behavioral responses. In such an organism, genetic factors might exert a stronger influence on behavior than environmental factors when compared to organisms with pronounced cortical signal integration. The above considerations to explain potentially differing organizations of signal flow within basal ganglio-thalamocortical and cerebello-thalamo-cortical loops should have a detectable effect on behavioral levels. Such effects might be revealed by comparing behavior in networks that exhibit different degrees of convergences on thalamic levels (e.g., oculomotor versus skeletomotor). Comparing changes in their behavioral output due to pathologies of basal ganglia (e.g., Parkinson's disease) or cerebellum (e.g., cerebellar ataxia) might further highlight the importance to study such differences in network organization. 


\section{Conclusion}

Although numerous amounts of studies exist analyzing the existence of convergences of BG and the cerebellar territory in the thalamus, the results of these different studies are partially conflicting: three neuronal patterns of information processing are presented: (1) a segregation of the cerebellar and BG territories; (2) an interdigitating pattern; and (3) an overlap between both territories. Most of these studies postulate a segregation of the cerebellar and BG projections reflected by interdigitating patterns and some studies described a potential overlap, predominantly in border regions.

To sum up, the amount of convergences has diminished from rodents to carnivores to primates. Interestingly, new evidence from reconstruction based on phylogenetically informative retroposons (Kriegs et al. 2006) suggests that humans and rats developed on another branch then carnivores, and hence, evolution might not have a strong role here. Despite the increasing complexity of informational flow and processing, it might also be possible that the amount of overlap just decreased due to extensive brain growth. In general, a trend to greater network complexity is apparent in larger brains indicating that this complexity is required for maintaining stable levels of neural activation (Kaiser and Hilgetag 2010): larger brains maintain larger-size networks to possess a larger number of hierarchical levels or more modules. Hence, this might call for more specialised regions in primates.

In this review, we introduce two basal organizational principals: (a) "core and shell" principle and (b) networkspecific convergence. Herewith, our review scratches on a general principle in information processing, which might change from rodents to the human being due to complexity of informational flow. The analysis of the presence of such convergences, however, might help to step forward to the understanding of movement disorders such as Parkinson's disease or dystonia, where a dysfunction in the interplay between these two subcortical systems is highly probable.

Acknowledgements Open access funding provided by Max Planck Society.

Open Access This article is distributed under the terms of the Creative Commons Attribution 4.0 International License (http://creativecommons.org/licenses/by/4.0/), which permits unrestricted use, distribution, and reproduction in any medium, provided you give appropriate credit to the original author(s) and the source, provide a link to the Creative Commons license, and indicate if changes were made.

\section{References}

Agnati LF, Guidolin D, Guescini M, Genedani S, Fuxe K (2010) Understanding wiring and volume transmission. Brain Res Rev 64(1):137-159. https://doi.org/10.1016/j.brainresrev.2010.03.003

Anderson ME, DeVito JL (1987) An analysis of potentially converging inputs to the rostral ventral thalamic nuclei of the cat. Cell Tissue Res 68(2):260-276. https://doi.org/10.1007/BF00248792

Anderson ME, Turner RS (1991) Activity of neurons in cerebellarreceiving and pallidal-receiving areas of the thalamus of the behaving monkey. J Neurophysiol 66(3):879-893

Arecchi-Bouchhioua P, Yelnik J, Francois C, Percheron G, Tandé D (1997) Three-dimensional morphology and distribution of pallidal axons projecting to both the lateral region of the thalamus and the central complex in primates. Brain Res 754(1-2):311-314. https://doi.org/10.1016/S0006-8993(97)00181-9

Asanuma C, Thach WT, Jones EG (1983a) Anatomical evidence for segregated focal groupings of efferent cells and their terminal ramifications in the cerebellothalamic pathway of the monkey. Brain Res Rev 5(3):267-297. https://doi. org/10.1016/0165-0173(83)90016-4

Asanuma C, Thach WT, Jones EG (1983b) Brainstem and spinal projections of the deep cerebellar nuclei in the monkey, with observations on the brainstem projections of the dorsal column nuclei. Brain Res Rev 286(3):299-322

Bava A, Manzoni T, Urbano A (1967) Effects of fastigial stimulation on thalamic neurones belonging to the diffuse projection system. Brain Res 4(4):378-380. https://doi. org/10.1016/0006-8993(67)90168-0

Bava A, Cicirata F, Licciardello S, Li Volsi G, Pantò MR (1979) Fastigial nuclei projections on the ventralis lateralis (VL) thalamic nucleus neurons. Brain Res 168(1):169-175

Berkley KJ (1983) Spatial relationships between the terminations of somatic sensory motor pathways in the rostral brainstem of cats and monkeys. II. Cerebellar projections compared with those of the ascending somatic sensory pathways in lateral diencephalon. J Neurochem 220(2):229-251. https://doi.org/10.1002/ cne. 902200210

Berman AL (1968) The brain stem of the cat: a cytoarchitectonic atlas with stereotaxic coordinates. U. Wisconsin Press, Madison

Berman AL, Jones EG (1982) The thalamus and basal telencephalon of the cat: a cytoarchitectonic atlas with stereotaxic coordinates. University of Wisconsin Press Madison

Bonsi P, Cuomo D, De Persis C, Centonze D, Bernardi G, Calabresi P, Pisani A (2005) Modulatory action of metabotropic glutamate receptor (mGluR) 5 on mGluR1 function in striatal cholinergic interneurons. Neuropharmacol 49 Suppl 1:104-113. https://doi. org/10.1016/j.neuropharm.2005.05.012

Bostan AC, Strick PL (2010) The cerebellum and basal ganglia are interconnected. Neuropsychol Rev 20(3):261-270. https://doi. org/10.1007/s11065-010-9143-9

Bostan AC, Dum RP, Strick PL (2010) The basal ganglia communicate with the cerebellum. Proc Natl Acad Sci USA 107(18):84528456. https://doi.org/10.1073/pnas.1000496107

Bostan AC, Dum RP, Strick PL (2013) Cerebellar networks with the cerebral cortex and basal ganglia. Trends Cogn Neurosci 17(5):241-254. https://doi.org/10.1016/j.tics.2013.03.003

Boulton AA, Baker GB, Vanderwolf CH (1990) Neurophysiological techniques II, vol 15. Humana Press, New Jersey. https://doi. org/10.1385/0896031853

Buee J, Deniau JM, Chevalier G (1986) Nigral modulation of cerebellothalamo-cortical transmission in the ventral medial thalamic nucleus. Exp Brain Res 65(1):241-244 
Buford JA, Inase M, Anderson ME (1996) Contrasting locations of pallidal-receiving neurons and microexcitable zones in primate thalamus. J Neurophysiol 75(3):1105-1116

Carpenter MB, Brittin GM, Pines J (1958) Isolated lesions of the fastigial nuclei in the cat. J Neurochem 109(1):65-89. https://doi. org/10.1002/cne.901090104

Carpenter MB, Nakano K, Kim R (1976) Nigrothalamic projections in the monkey demonstrated by autoradiographic technics. J Neurochem 165(4):401-415. https://doi.org/10.1002/cne.901650402

Chan-Palay V (1977) Cerebellar dentate nucleus: Organization, cytology and transmitters. Springer, Berlin

Chen CH, Fremont R, Arteaga-Bracho EE, Khodakhah K (2014) Short latency cerebellar modulation of the basal ganglia. Nat Neurosci 17(12):1767-1775. https://doi.org/10.1038/nn.3868

Chevalier G, Deniau JM (1982) Inhibitory nigral influence on cerebellar evoked responses in the rat ventromedial thalamic nucleus. Cell Tissue Res 48(3):369-376. https://doi.org/10.1007/ BF00238613

Chivileva OG, Gorbachevskaya AI (2008) Projections of the basal ganglia to the zona incerta of the dog diencephalon. Neurosci Behav Physiol 38(7):743-746. https://doi.org/10.1007/ s11055-008-9040-3

Cornwall J, Phillipson OT (1988) Afferent projections to the parafascicular thalamic nucleus of the rat, as shown by the retrograde transport of wheat germ agglutinin. Brain Res Bull 20(2):139-150

Deniau JM, Lackner D, Feger J (1978) Effect of substantia nigra stimulation on identified neurons in the VL-VA thalamic complex: comparison between intact and chronically decorticated cats. Brain Res 145(1):27-35. https://doi. org/10.1016/0006-8993(78)90793-X

Deniau JM, Kita H, Kitai ST (1992) Patterns of termination of cerebellar and basal ganglia efferents in the rat thalamus. Strictly segregated and partly overlapping projections. Neurosci Lett 144(1-2):202-206

Desiraju T, Purpura DP (1969) Synaptic convergence of cerebellar and lenticular projections to thalamus. Brain Res 15(2):544-547. https://doi.org/10.1016/0006-8993(69)90180-2

Dewulf A, van Winsen T (1971) Anatomy of the normal human thalamus: topometry and standardized nomenclature. Elsevier Publishing Company, Amsterdam

Di Chiara G, Porceddu ML, Morelli M, Mulas ML, Gessa GL (1979) Evidence for a gabaergic projection from the substantia nigra to the ventromedial thalamus and to the superior colliculus of the rat. Brain Res 176(2):273-284. https://doi. org/10.1016/0006-8993(79)90983-1

Doya K (2000) Complementary roles of basal ganglia and cerebellum in learning and motor control. Curr Op Neurobiol 10(6):732739. https://doi.org/10.1016/S0959-4388(00)00153-7

Faull RLM, Carman JB (1968) Ascending projections of the substantia nigra in the rat. J Neurochem 132(1):73-91. https://doi. org/10.1002/cne.901320104

Faull RLM, Carman JB (1978) The cerebellofugal projections in the brachium conjunctivum of the rat. I. The contralateral ascending pathway. J Neurochem 178(3):495-517. https://doi.org/10.1002/ cne. 901780307

Gallay MN, Jeanmonod D, Liu J, Morel A (2008) Human pallidothalamic and cerebellothalamic tracts: anatomical basis for functional stereotactic neurosurgery. Brain Struct Func 212(6):443463. https://doi.org/10.1007/s00429-007-0170-0

Gauchy C, Kemel ML, Romo R, Chéramy A, Glowinski J, Besson MJ (1983) Effects of nigral application of muscimol on release of $[3 \mathrm{H}] \gamma$-aminobutyrate and on multi-unit activity in various cat thalamic nuclei. Neuroscience 10(3):781-788. https://doi. org/10.1016/0306-4522(83)90215-4

Gazzara RA, Fisher RS, Levine MS, Hull CD, Buchwald NA (1986) Physiological and morphological analyses of ventral anterior and ventral lateral thalamic neurons in the cat. Brain Res 397(2):225-237

Gerfen CR, Staines WA, Fibiger HC, Arbuthnott GW (1982) Crossed connections of the substantia nigra in the rat. J Neurochem 207(3):283-303. https://doi.org/10.1002/cne.902070308

Goldman-Rakic PS (1984) Modular Organization of Prefrontal Cortex. Trends Neurosci 7(11):419-424. https://doi.org/10.1016/ S0166-2236(84)80146-0

Haber SN (2016) Corticostriatal circuitry. Dialogues Clin Neurosci 18(1):7-21

Haber SN, Adler A, Bergman H (2012) Chap. 20-the basal ganglia. In: Mai JK, Paxinos G (eds). Academic Press, San Diego, pp 678-738

Harding BN (1973) An ultrastructural study of the centre median and ventrolateral thalamic nuclei of the monkey. Brain Res 54:335340. https://doi.org/10.1016/0006-8993(73)90057-7

Haroian AJ, Massopust LC, Young PA (1981) Cerebellothalamic projections in the rat: an autoradiographic and degeneration study. J Neurochem 197(2):217-236. https://doi.org/10.1002/ cne.901970205

Hassler R (1950) Anatomy of the thalamus. Archiv fur Psychiatrie und Nervenkrankheiten, vereinigt mit Zeitschrift fur die gesamte. Neurologie Psychiatrie 184(3-4):249-256

Hendry SHC, Jones EG, Graham J (1979) Thalamic relay nuclei for cerebellar and certain related fiber systems in the cat. J Neurochem 185(4):679-713. https://doi.org/10.1002/cne.901850406

Herkenham M, Nauta WJ (1979) Efferent connections of the habenular nuclei in the rat. J Comp Neurol 187(1):19-47. https://doi. org/10.1002/cne.901870103

Hoshi E, Tremblay L, Féger J, Carras PL, Strick PL (2005) The cerebellum communicates with the basal ganglia. Nat Neurosci 8(11):1491-1493. https://doi.org/10.1038/nn1544

Ichinohe N, Mori F, Shoumura K (2000) A di-synaptic projection from the lateral cerebellar nucleus to the laterodorsal part of the striatum via the central lateral nucleus of the thalamus in the rat. Brain Res 880(1-2):191-197

Ikai Y, Takada M, Shinonaga Y, Mizuno N (1992) Dopaminergic and non-dopaminergic neurons in the ventral tegmental area of the rat project, respectively, to the cerebellar cortex and deep cerebellar nuclei. Neuroscience 51(3):719-728

Ilinsky IA, Kultas-Ilinsky K (1984) An autoradiographic study of topographical relationships between pallidal and cerebellar projections to the cat thalamus. Exp Brain Res 54(1):95-106

Ilinsky IA, Kultas-Ilinsky K (1987) Sagittal cytoarchitectonic maps of theMacaca mulatta thalamus with a revised nomenclature of the motor-related nuclei validated by observations on their connectivity. J Neurochem 262(3):331-364. https://doi.org/10.1002/ cne. 902620303

Ilinsky IA, Jouandet ML, Goldman-Rakic PS (1985) Organization of the nigrothalamocortical system in the rhesus monkey. J Comp Neurol 236(3):315-330. https://doi.org/10.1002/cne.902360304

Inase M, Tanji J (1995) Thalamic distribution of projection neurons to the primary motor cortex relative to afferent terminal fields from the globus pallidus in the macaque monkey. J Comp Neurol 353(3):415-426. https://doi.org/10.1002/cne.903530309

Jbabdi S, Sotiropoulos SN, Haber SN, Van Essen DC, Behrens TE (2015) Measuring macroscopic brain connections in vivo. Nat Neurosci 18(11):1546-1555. https://doi.org/10.1038/nn.4134

Jimenez-Castellanos J, Reinoso-Su rez F (1985) Topographical organization of the afferent connections of the principal ventromedial thalamic nucleus in the cat. J Comp Neurol 236(3):297-314. https://doi.org/10.1002/cne.902360303

Jinnai K, Nambu A, Tanibuchi I, Yoshida S-i (1993) Cerebelloand pallido-thalamic pathways to areas 6 and 4 in the monkey. Stereotact Funct Neurosurg 60(1-3):70-79. https://doi. org/10.1159/000100591 
Jones EG (2007) The thalamus, 2nd. Cambridge University Press, Cambridge

Kaiser M, Hilgetag CC (2010) Optimal hierarchical modular topologies for producing limited sustained activation of neural networks. Front Neuroinform 4:8. https://doi.org/10.3389/fninf.2010.00008

Kalil K (1981) Projections of the cerebellar and dorsal column nuclei upon the thalamus of the rhesus monkey. J Neurochem 195(1):25-50. https://doi.org/10.1002/cne.901950105

Kim R, Nakano K, Jayaraman A, Carpenter MB (1976) Projections of the globus pallidus and adjacent structures: an autoradiographic study in the monkey. J Neurochem 169(3):263-289. https://doi. org/10.1002/cne.901690302

Krauth A, Blanc R, Poveda A, Jeanmonod D, Morel A, Székely G (2010) A mean three-dimensional atlas of the human thalamus: generation from multiple histological data. NeuroImage 49(3):2053-2062. https://doi.org/10.1016/j. neuroimage.2009.10.042

Krettek JE, Price JL (1977) The cortical projections of the mediodorsal nucleus and adjacent thalamic nuclei in the rat. J Neurochem 171(2):157-191. https://doi.org/10.1002/cne.901710204

Kriegs JO, Churakov G, Kiefmann M, Jordan U, Brosius J, Schmitz J (2006) Retroposed elements as archives for the evolutionary history of placental mammals. PLoS Biol 4(4):e91. https://doi. org/10.1371/journal.pbio.0040091

Kultas-Ilinsky K, Ilinsky IA, Massopust LC, Young PA, Smith KR (1978) Nigrothalamic pathway in the cat demonstrated by autoradiography and electron microscopy. Cell Tissue Res 33(34):481-492. https://doi.org/10.1007/BF00235569

Kultas-Ilinsky K, Ilinsky IA, Young PA, Smith KR (1980) Ultrastructure of degenerating cerebellothalamic terminals in the ventral medial nucleus of the cat. Cell Tissue Res 38 (2). https://doi. org/10.1007/BF00236734

Kultas-Ilinsky K, Ilinsky IA, Verney C (2011) Glutamic acid decarboxylase isoform 65 immunoreactivity in the motor thalamus of humans and monkeys: $\gamma$-aminobutyric acidergic connections and nuclear delineations. J Comp Neurol 519(14):2811-2837. https:// doi.org/10.1002/cne.22653

Kuo J-S, Carpenter MB (1973) Organization of pallidothalamic projections in the rhesus monkey. J Neurochem 151(3):201-235. https://doi.org/10.1002/cne.901510302

Kuramoto E, Furuta T, Nakamura KC, Unzai T, Hioki H, Kaneko T (2009) Two Types of Thalamocortical Projections from the Motor Thalamic Nuclei of the Rat: A Single Neuron-Tracing Study Using Viral Vectors. Cereb Cortex 19(9):2065-2077. https://doi.org/10.1093/cercor/bhn231

Kuramoto E, Fujiyama F, Nakamura KC, Tanaka Y, Hioki H, Kaneko $\mathrm{T}$ (2010) Complementary distribution of glutamatergic cerebellar and GABAergic basal ganglia afferents to the rat motor thalamic nuclei. J Neurochem 33(1):95-109. https://doi. org/10.1111/j.1460-9568.2010.07481.x

Kusama T, Mabuchi M, Sumino T (1971) Cerebellar projections to the thalamic nuclei in monkeys. Proc Japan Acad 47:505-510

Lambert C, Simon H, Colman J, Barrick TR (2016) Defining thalamic nuclei and topographic connectivity gradients in vivo. Neuroimage. https://doi.org/10.1016/j.neuroimage.2016.08.028

Lerch JP, van der Kouwe AJW, Raznahan A, Paus T, Johansen-Berg H, Miller KL, Smith SM, Fischl B, Sotiropoulos SN (2017) Studying neuroanatomy using MRI. Nat Neurosci 20(3):314-326. https://doi.org/10.1038/nn.4501

MacLeod NK, James TA (1984) Regulation of cerebello-cortical transmission in the rat ventromedial thalamic nucleus. Exp Brain Res 55(3):535-552

MacLeod NK, James TA, Kilpatrick IC, Starr MS (1980) Evidence for a GABAergic nigrothalamic pathway in the rat. Cell Tissue Res 40(1):55-61. https://doi.org/10.1007/BF00236662
Mai JK, Forutan F (2012) Chap. 19-thalamus. In: Mai JK, Paxinos G (eds). Academic Press, San Diego, pp 618-677

McKenzie JS (2009) The subthalamic region of Luys, Forel, and Dejerine. In: Groenewegen HJ, Voorn P, Berendse HW, Mulder AB, Cools AR (eds) The basal ganglia IX. Springer New York, pp 97-107. https://doi.org/10.1007/978-1-4419-0340-2_8

McMasters RE, Russell GV (1958) Efferent pathways from the deep cerebellar nuclei of the cat. J Comp Neurol 110(2):205-219. https://doi.org/10.1002/cne.901100204

Melchitzky D (2000) Tyrosine hydroxylase- and dopamine transporterimmunoreactive axons in the primate cerebellum evidence for a lobular- and laminar-specific dopamine innervation. Neuropsychopharmacol 22(5):466-472. https://doi.org/10.1016/ S0893-133X(99)00139-6

Middleton FA, Strick PL (2000) Basal ganglia and cerebellar loops: motor and cognitive circuits. Brain Res Rev 31(2-3):236-250

Milardi D, Arrigo A, Anastasi G, Cacciola A, Marino S, Mormina E, Calamuneri A, Bruschetta D, Cutroneo G, Trimarchi F, Quartarone A (2016) Extensive direct subcortical cerebellum-basal ganglia connections in human brain as revealed by constrained spherical deconvolution tractography. Front Neuroanat 10:29. https://doi.org/10.3389/fnana.2016.00029

Miyamoto Y, Jinnai K (1994) The inhibitory input from the substantia nigra to the mediodorsal nucleus neurons projecting to the prefrontal cortex in the cat. Brain Res 649(1-2):313-318. https:// doi.org/10.1016/0006-8993(94)91079-0

Morecraft RJ, Ugolini G, Lanciego JL, Wouterlood FG, Pandya DN (2009) Chap. 13 - classic and contemporary neural tract tracing techniques. In: Johansen-Berg H, Behrens TEJ (eds). Academic Press, San Diego, pp 272-308

Nambu A, Yoshida S, Jinnai K (1988) Projection on the motor cortex of thalamic neurons with pallidal input in the monkey. Cell Tissue Res 71(3):658-662. https://doi.org/10.1007/BF00248759

Nauta WJH, Mehler WR (1966) Projections of the lentiform nucleus in the monkey. Brain Res 1(1):3-42. https://doi. org/10.1016/0006-8993(66)90103-X

Neychev VK, Fan X, Mitev VI, Hess EJ, Jinnah HA (2008) The basal ganglia and cerebellum interact in the expression of dystonic movement. Brain 131(Pt 9):2499-2509. https://doi. org/10.1093/brain/awn168

Nieuwenhuys R, Voogd J, Voogd J, van Huijzen C (2008) The human central nervous system, 3 edn. Springer Berlin Heidelberg, Germany

Niimi K, Kusunose M, Ono K, Yanagihara M (1990) Brainstem afferents to the intralaminar nuclei of the cat thalamus studied by the horseradish peroxidase method. J Hirnforsch 31(1):107-122

Okubo Y, Iino M (2011) Visualization of glutamate as a volume transmitter. J Physiol 589(3):481-488. https://doi.org/10.1113/ jphysiol.2010.199539

Olszewski J (1952) The thalamus of the Macaca, mulatta. An atlas for use with the stereotaxic instrument. New York, S. Karger, Basle Switzerland

Ono K, Niimi K (1986) Afferent projections to the thalamic mediodorsal nucleus in the cat studied by retrograde and anterograde axonal transport of horseradish peroxidase. J Hirnforsch 27(6):597-610

Onodera S, Hicks TP (1995) Patterns of transmitter labelling and connectivity of the cat\&apos;s nucleus of Darkschewitsch: A wheat germ agglutinin-horseradish peroxidase and immunocytochemical study at light and electron microscopical levels. J Comp Neurol 361(4):553-573. https://doi.org/10.1002/ cne. 903610402

Onodera S, Hicks TP (1998) Projections from substantia nigra and zona incerta to the cat\&apos;s nucleus of Darkschewitsch. J Comp Neurol 396(4):461-482 
Onodera S, Hicks TP (2009) A comparative neuroanatomical study of the red nucleus of the cat, macaque and human. PLoS One 4(8):e6623. https://doi.org/10.1371/journal.pone.0006623

Parent A, Hazrati L-N (1995a) Functional anatomy of the basal ganglia. II. The place of subthalamic nucleus and external pallidium in basal ganglia circuitry. Brain Res Rev 20(1):128-154. https://doi. org/10.1016/0165-0173(94)00008-D

Parent A, Hazrati LN (1995b) Functional anatomy of the basal ganglia. I. The cortico-basal ganglia-thalamo-cortical loop. Brain Res Rev 20(1):91-127

Parent A, Mackey A, Smith Y, Boucher R (1983) The output organization of the substantia nigra in primate as revealed by a retrograde double labeling method. Neuroscience 10(4):529-537. https:// doi.org/10.1016/0361-9230(83)90151-X

Paxinos G, Watson C (2006) The rat brain in stereotaxic coordinates: hard cover edition. Hard Cover edn. Academic Press, online

Paxinos G, Huang X-F, Toga AW (1999) The rhesus monkey brain in stereotaxic coordinates. Academic Press, San Diego

Pearson JC, Norris JR, Phelps CH (1984) The cytoarchitecture and some efferent projections of the centromedian-parafascicular complex in the lesser bushbaby (Galago senegalensis). J Neurochem 225(4):554-569. https://doi.org/10.1002/cne.902250406

Pellegrino LJ, Cushman AJ (1967) A stereotaxic atlas of the rat brain. Appleton-Century-Crofts New York

Pelzer EA, Hintzen A, Goldau M, von Cramon DY, Timmermann L, Tittgemeyer M (2013) Cerebellar networks with basal ganglia: feasibility for tracking cerebello-pallidal and subthalamo-cerebellar projections in the human brain. Eu J Neurosci 38(8):31063114. https://doi.org/10.1111/ejn.12314

Pelzer EA, Melzer C, Timmermann L, von Cramon DY, Tittgemeyer M (2017) Basal ganglia and cerebellar interconnectivity within the human thalamus. Brain Struct Func 222(1):381-392. https:// doi.org/10.1007/s00429-016-1223-z

Percheron G (1977) The thalamic territory of cerebellar afferents and the lateral region of the thalamus of the macaque in stereotaxic ventricular coordinates. J Hirnforsch 18:375-400

Percheron G, François C, Talbi B, Yelnik J, Fénelon G (1996) The primate motor thalamus. Brain Res Rev 22(2):93-181

Person RI, Andrezik JA, Dormer KJ, Foreman RD (1986) Fastigial nucleus projections in the midbrain and thalamus in dogs. Neuroscience 18(1):105-120

Plaha P, Khan S, Gill SS (2008) Bilateral stimulation of the caudal zona incerta nucleus for tremor control. J Neurol Neurosurg 79(5):504-513. https://doi.org/10.1136/jnnp.2006.112334

Platt SR (2007) The role of glutamate in central nervous system health and disease-a review. Vet J 173(2):278-286. https:// doi.org/10.1016/j.tvj1.2005.11.007

Pong M, Horn KM, Gibson AR (2008) Pathways for control of face and neck musculature by the basal ganglia and cerebellum. Neuroscience 58(2):249-264. https://doi.org/10.1016/j. brainresrev.2007.11.006

Rouiller EM, Liang F, Babalian A, Moret V, Wiesendanger M (1994) Cerebellothalamocortical and pallidothalamocortical projections to the primary and supplementary motor cortical areas: a multiple tracing study in macaque monkeys. J Comp Neurol 345(2):185-213. https://doi.org/10.1002/cne.903450204

Royce GJ, Bromley S, Gracco C (1991) Subcortical projections to the centromedian and parafascicular thalamic nuclei in the cat. J Comp Neurol 306(1):129-155. https://doi.org/10.1002/ cne.903060110

Sadikot AF, Rymar VV (2009) The primate centromedian-parafascicular complex: anatomical organization with a note on neuromodulation. Brain Res Bull 78(2-3):122-130. https://doi. org/10.1016/j.brainresbull.2008.09.016

Sakai ST, Patton K (1993) Distribution of cerebellothalamic and nigrothalamic projections in the dog: A double anterograde tracing study. J Comp Neurol 330(2):183-194. https://doi. org/10.1002/cne.903300204

Sakai ST, Inase M, Tanji J (1996) Comparison of cerebellothalamic and pallidothalamic projections in the monkey (Macaca fuscata): a double anterograde labeling study. J Comp Neurol 368(2):215-228. https://doi.org/10.1002/(SICI)10969861(19960429)368:2<215::AID-CNE4>3.0.CO;2-6

Sakai ST, Inase M, Tanji J (1999) Pallidal and cerebellar inputs to thalamocortical neurons projecting to the supplementary motor area in Macaca fuscata: a triple-labeling light microcopic study. Anat Embriol 199(1):9-19. https://doi.org/10.1007/ s004290050204

Sakai ST, Stepniewska I, Qi HX, Kaas JH (2000) Pallidal and cerebellar afferents to pre-supplementary motor area thalamocortical neurons in the owl monkey: a multiple labeling study. J Comp Neurol 417(2):164-180

Sakai ST, Inase M, Tanji J (2002) The relationship between MI and SMA afferents and cerebellar and pallidal efferents in the macaque monkey. Somatosens Mot Res 19(2):139-148. https:// doi.org/10.1080/08990220220131533

Schaltenbrand G, Wahren W, Hassler RG (1977) Atlas for stereotaxy of the human brain: with an accompanying guide. Architectonic Organization of the Thalamic Nuclei, Thieme

Schell GR, Strick PL (1984) The origin of thalamic inputs to the arcuate premotor and supplementary motor areas. J Neurosci 4(2):539-560

Schmierer K, Thavarajah JR, An SF, Brandner S, Miller DH, Tozer DJ (2010) Effects of formalin fixation on magnetic resonance indices in multiple sclerosis cortical gray matter. J Magn Reson Imag 32(5):1054-1060. https://doi.org/10.1002/jmri.22381

Schneider JS, Manetto C, Lidsky TI (1985) Substantia nigra projection to medullary reticular formation: Relevance to oculomotor and related motor functions in the cat. Neuroscience 62(1):1-6. https://doi.org/10.1016/0304-3940(85)90275-7

Shammah-Lagnado SJ, Ricardo JA, Sakamoto NT, Negrão N (1983) Afferent connections of the mesencephalic reticular formation: a horseradish peroxidase study in the rat. Neuroscience 9(2):391-409

Shammah-Lagnado SJ, Negra o N, Silva BA, Ricardo JA (1987) Afferent connections of the nuclei reticularis pontis oralis and caudalis: a horseradish peroxidase study in the rat. Neuroscience 20(3):961-989. https://doi.org/10.1016/0306-4522(87)90256-9

Shammah-Lagnado SJ, Costa MSMO., Ricardo JA (1992) Afferent connections of the parvocellular reticular formation: a horseradish peroxidase study in the rat. Neuroscience 50(2):403-425. https://doi.org/10.1016/0306-4522(92)90433-3

Sidib M, Par J-Fo, Smith Y (2002) Nigral and pallidal inputs to functionally segregated thalamostriatal neurons in the centromedian/ parafascicular intralaminar nuclear complex in monkey. J Neurochem 447(3):286-299. https://doi.org/10.1002/cne.10247

Sidibé M, Bevan MD, Bolam JP, Smith Y (1997) Efferent connections of the internal globus pallidus in the squirrel monkey: I. Topography and synaptic organization of the pallidothalamic projection. J Comp Neurol 382(3):323-347

Snider RS, Niemer WT (1961) A stereotaxic atlas of the cat brain. University of Chicago Press, Chicago

Stanton GB (1980) Topographical organization of ascending cerebellar projections from the dentate and interposed nuclei in Macaca mulatta: an anterograde degeneration study. J Comp Neurol 190(4):699-731. https://doi.org/10.1002/cne.901900406

Stüber C, Morawski M, Schäfer A, Labadie C, Wähnert M, Leuze C, Streicher M, Barapatre N, Reimann K, Geyer S, Spemann D, Turner RS (2014) Myelin and iron concentration in the human brain: a quantitative study of MRI contrast. NeuroImage $93 \mathrm{Pt}$ 1:95-106. https://doi.org/10.1016/j.neuroimage.2014.02.026 
Sugimoto T, Mizuno N, Itoh K (1981) An autoradiographic study on the terminal distribution of cerebellothalamic fibers in the cat. Brain Res 215(1-2):29-47

Tanaka M, Kunimatsu J (2011) Contribution of the central thalamus to the generation of volitional saccades. J Neurochem 33(11):20462057. https://doi.org/10.1111/j.1460-9568.2011.07699.x

Tanibuchi I, Kitano H, Jinnai K (2009) Substantia nigra output to prefrontal cortex via thalamus in monkeys. I. Electrophysiological identification of thalamic relay neurons. J Neurophysiol 102(5):2933-2945. https://doi.org/10.1152/jn.91287.2008

Tseng GF, Royce GJ (1986) A Golgi and ultrastructural analysis of the centromedian nucleus of the cat. J Comp Neurol 245(3):359-378. https://doi.org/10.1002/cne.902450306

Ueki A (1983) The mode of nigro-thalamic transmission investigated with intracellular recording in the cat. Exp Brain Res 49(1):116-124

Ueki A, Uno M, Anderson M, Yoshida M (1977) Monosynaptic inhibition of thalamic neurons produced by stimulation of the substantia nigra. Experientia 33(11):1480-1482. https://doi.org/10.1007/ BF01918820

Uno M, Yoshida M (1975) Monosynaptic inhibition of thalamic neurons produced by stimulation of the pallidal nucleus in cats. Brain Res 99(2):377-380. https://doi.org/10.1016/0006-8993(75)90040-2

Uno M, Ozawa N, Yoshida M (1978) The mode of pallido-thalamic transmission investigated with intracellular recording from cat thalamus. Cell Tissue Res 33(3-4):493-507. https://doi. org/10.1007/BF00235570

Uusisaari MY, Knöpfel T (2012) Diversity of neuronal elements and circuitry in the cerebellar nuclei. Cell Tissue Res 11(2):420-421. https://doi.org/10.1007/s12311-011-0350-6

van Duijn S, Nabuurs RJA, van Rooden S, Maat-Schieman MLC, van Duinen SG, van Buchem MA, van der Weerd L, Natté $R$ (2011) MRI artifacts in human brain tissue after prolonged formalin storage. Magn Reson Med 65(6):1750-1758. https:// doi.org/10.1002/mrm.22758

Voogd J, Ruigrok TJH (2012) Chap. 15-cerebellum and precerebellar nuclei. In: Mai JK, Paxinos G (eds). Academic Press, San Diego, pp 471-545

Westby GWM, Collinson C, Redgrave P, Dean P (1994) Opposing excitatory and inhibitory influences from the cerebellum and basal ganglia converge on the superior colliculus: an electrophysiological investigation in the rat. J Neurochem 6(8):1335-1342. https://doi.org/10.1111/j.1460-9568.1994.tb00324.x

Wiklund L, Cuénod M (1984) Differential labelling of afferents to thalamic centromedian-parafascicular nuclei with $[3 \mathrm{H}]$ choline and $\mathrm{d}-[3 \mathrm{H}]$ aspartate: Further evidence for transmitter specific retrograde labelling. Neurosci lett 46(3):275-281. https://doi. org/10.1016/0304-3940(84)90112-5

Yamamoto T, Hassler R, Huber C, Wagner A, Sasaki K (1983) Electrophysiologic studies on the pallido- and cerebellothalamic projections in squirrel monkeys (Saimiri sciureus). Cell Tissue Res 51 (1). https://doi.org/10.1007/BF00236805

Yamamoto T, Noda T, Miyata M, Nishimura Y (1984) Electrophysiological and morphological studies on thalamic neurons receiving entopedunculo- and cerebello-thalamic projections in the cat. Neuroscience 301(2):231-242. https://doi. org/10.1016/0006-8993(84)91091-6

Yamamoto T, Noda T, Samejima A, Oka H (1985) A morphological investigation of thalamic neurons by intracellular hrp staining in cats. J Neurochem 236(3):331-347. https://doi.org/10.1002/ cne.902360305

Yamamoto T, Yoshida K, Yoshikawa H, Kishimoto Y, Oka H (1992) The medial dorsal nucleus is one of the thalamic relays of the cerebellocerebral responses to the frontal association cortex in the monkey: horseradish peroxidase and fluorescent dye double staining study. Brain Res 579(2):315-320 